\title{
Experimental Study on the Soil Conditioning Materials for EPB Shield Tunneling in Silty Sand
}

\author{
Chi-Hao Cheng $\mathbb{D}^{1,2}$ Shao-Ming Liao $\mathbb{D}^{1},{ }^{1}$ Xiao-Bo Huo $\mathbb{D}^{3},{ }^{3}$ and Li-Sheng Chen $\mathbb{D}^{4}$ \\ ${ }^{1}$ Department of Geotechnical Engineering, Tongji University, 1239 Siping Road, Shanghai 200092, China \\ ${ }^{2}$ Shenzhen Tagen Group Co., Ltd., Shenzhen 518034, China \\ ${ }^{3}$ Shanxi Electric Power Survey and Design Institute, Taiyuan 030001, China \\ ${ }^{4}$ Shanghai Urban Construction Municipal Engineering (Group) Co., Ltd., Shanghai 200065, China \\ Correspondence should be addressed to Shao-Ming Liao; metroshield@foxmail.com
}

Received 22 September 2020; Revised 18 November 2020; Accepted 27 November 2020; Published 17 December 2020

Academic Editor: Zhushan Shao

Copyright $\odot 2020$ Chi-Hao Cheng et al. This is an open access article distributed under the Creative Commons Attribution License, which permits unrestricted use, distribution, and reproduction in any medium, provided the original work is properly cited.

\begin{abstract}
Earth pressure balance (EPB) shield tunneling in a silty sand stratum is frequently faced with the wear of rotary cutter disc, clogging, or even collapse of workface due to its noncohesive and discrete properties of silty sand material. Soil conditioning is an effective way to reduce the discrete and friction properties of silty sand and to increase its rheology and fluidity, thus improving the cutting performance of EPB machines. However, soil conditioning materials were generally prepared and injected based on past limited field experiences or lab tests which were far from reality. In this article, a ground suitability test system for simulating shield tunneling in a conditioned ground was specially developed and used in a series of tests to investigate the influences of key factors of soil conditioning on the shield cutting performance. In addition, a field experiment of shield tunneling in silty sand of Wuhan Metro was conducted for verification. The major findings were obtained as follows. (1) The proposed test system performed well in simulating and assessing the cutting performance of EPB shield in conditioned soils, and the test results agreed well with the field test. (2) The soil conditioning materials can significantly reduce the cutting torque of shield tunneling in silty sand by up to $60 \%-70 \%$. (3) The optimal foam and slurry parameters are suggested in the paper for shield tunneling in silty sand, respectively. (4) The test results reveal that the slurry conditioning is better than the foam in decreasing the cutter torque in silty sand. To achieve the same effect of soil conditioning, the injection ratios of foam and slurry should be $45 \%$ and $10 \%$, respectively, to achieve the torque reduction ratio of $60 \%$. These findings can provide a practical reference for engineers to determine the bestfit conditioning materials and construction parameters in the silty sand stratum.
\end{abstract}

\section{Introduction}

Tunnel engineering has played a very important role in the rapid development of infrastructure construction [1-4]. Massive earth pressure balance (EPB) shields have been put into building comprehensive networks of underground transportation in megacities of China and around the world [5-8]. However, the widespread unfavorable geologic conditions often severely hamper the normal operation of this mechanized tunneling equipment [3,9-11]. For instance, the shield tunneling in sand is prone to serious abrasion of cutter disk, downtime of advancement, and even collapse of the workface [12-14]. The use of soil conditioning material is an effective way to improve the applicability of EPB shields in different geological conditions [15-17].

Many researchers and engineers have paid much attention to the soil conditioning materials and their injection parameters, as well as their effects on the shield driving performance [18-29]. Wei [30] proposed that excavated soils should ideally have a "paste flow" (e.g., low inner friction, preferable consistency, low permeability, and compressibility). Massive projects [31-35] considered the injection of conditioning agents such as foams, bentonite slurry, and polymers ahead of the cutter head, into the working chamber, and along the screw conveyor, to mix with the original soil during the excavation process. Peila et al. [36] 
performed a slump test to evaluate the flowability of conditioned soils, reaching a consensus that the ideal slump value is $100-250 \mathrm{~mm}$ [37-40]. Although the slump test is easy to perform and can reflect an overall plastic index on the behavior of the conditioned soil, the state of the prepared conditioned sample in the test is quite different from its actual states at the shield workface or in its working chamber. Several experimental devices have been developed to simulate the operation of shield machines [39, 41-48]. Sotiris et al. [46] utilized a mixing apparatus to simulate the mixing process in a shielded chamber so that the friction properties of conditioned soils can be assessed based on the difficulty in mixing. Merritt [42], Peila et al. [39], Rivas et al. [45], and Thewes and Budach [47] developed microscrew conveyor models for laboratory tests to investigate the performance of conditioned soils based on different screw speeds and tank pressures. Nevertheless, most of these experiments were carried out at atmospheric pressure without considering soil confining pressure and thus still far from application to field construction. In fact, the soils at the excavation face and in the working chamber or screws are under highly variable confining pressures. Therefore, it is necessary to perform a close-to-field dynamic simulation test on the relationship between the shield cutting performance and soil conditioning.

In this paper, a special ground suitability test system for simulating shield driving was developed, and a series of tests were conducted to investigate the effect of different conditioners on the shield cutting performance. The simulation test considered four key factors (moisture content, soil pressure, soil conditioner type, and injection ratio) that affect soil conditioning performance the most. Finally, the laboratory test results were verified by the field observations of a real tunneling project in Wuhan, China.

\section{Test Setup}

The test system consists of a main test device and two soil conditioning devices (a foaming device and a slurry device), as shown in Figure 1. The main test device was designed and manufactured to simulate the cutting and driving process of shield machine and automatically to measure and record the interactions between the cutter head and soils. The foaming device was used for foam generation and injection for different foaming materials. The slurry device was used for preparation and injection of bentonite slurry into the cutter head.

2.1. Foaming Device. Figure 2 shows the working principle of the foam generator, which consists mainly of a feeding system, air control system, foam mixer, and foam generator connected in series with a reducing valve, pressure gauge, flowmeter, and stop valve to gather and regulate the pressure and flow in the air and liquid mixer. Firstly, the foaming material is stored in the storage silo and connected to the air and liquid mixer. Then, it is delivered to the air-liquid mixer by the air compressor. Finally, the foam is produced by the

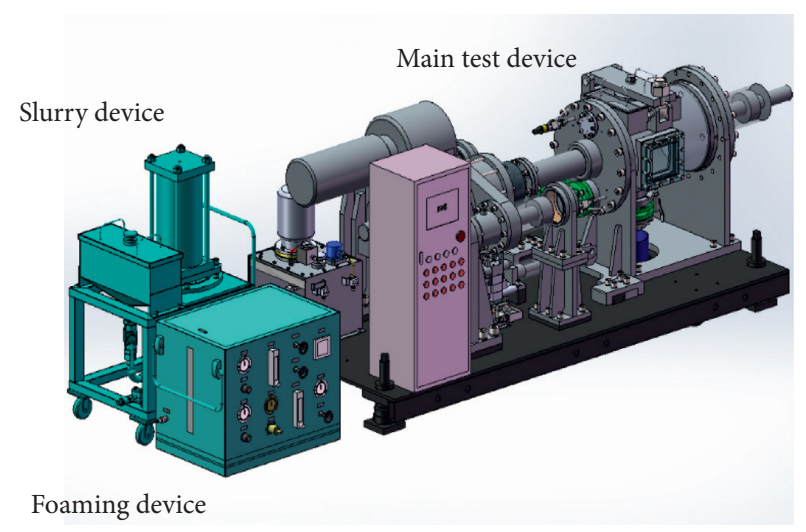

Figure 1: Ground suitability test system for EPB tunneling.

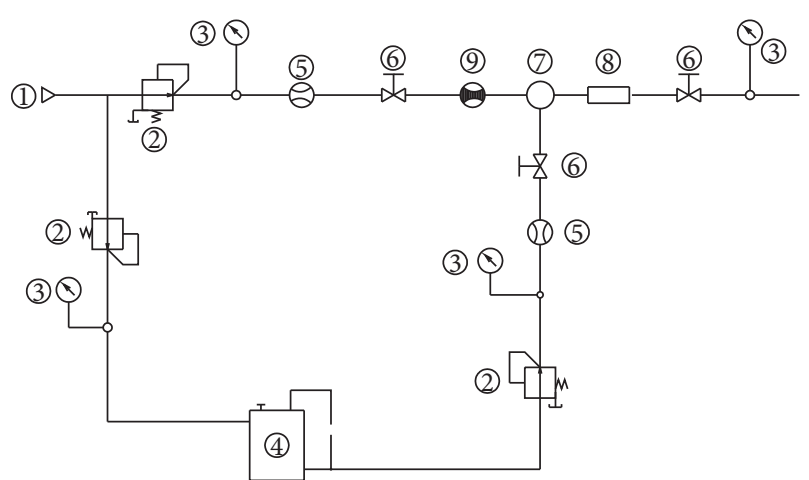

Figure 2: System schematic of foam device. 1, air compressor; 2, reducing valve; 3 , pressure gage; 4 , storage silo; 5 , flowmeter; 6 , stop valve; 7 , air and liquid mixer; 8 , foam generator; 9 , air flow sensor.

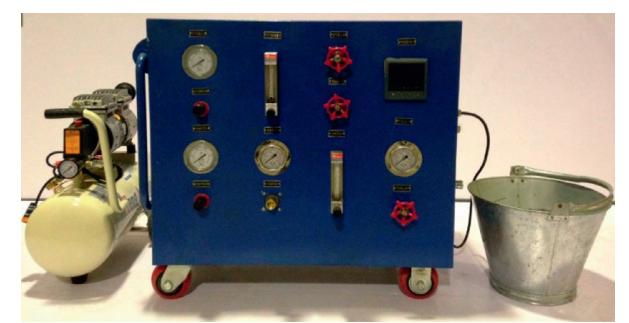

Figure 3: Image of foam generator.

foam generator after thorough mixing. Figure 3 shows an image of the assembled foaming device, and the dimension is 0.6 meters long, 0.4 meters wide, and 0.6 meters high.

2.2. Slurry Device. The slurry device mainly includes a storage silo, syringe, and cylinder (Figure 4). The dimension of length, width, and height is 0.7 meters, 0.53 meters, and 1.3 meters. The prepared slurry is transferred from the storage silo to the syringe by controlling the ball valve. Then, the slurry is injected into the drain pipe by the extension of the cylinder. The injection pressure and rate are automatically recorded. 


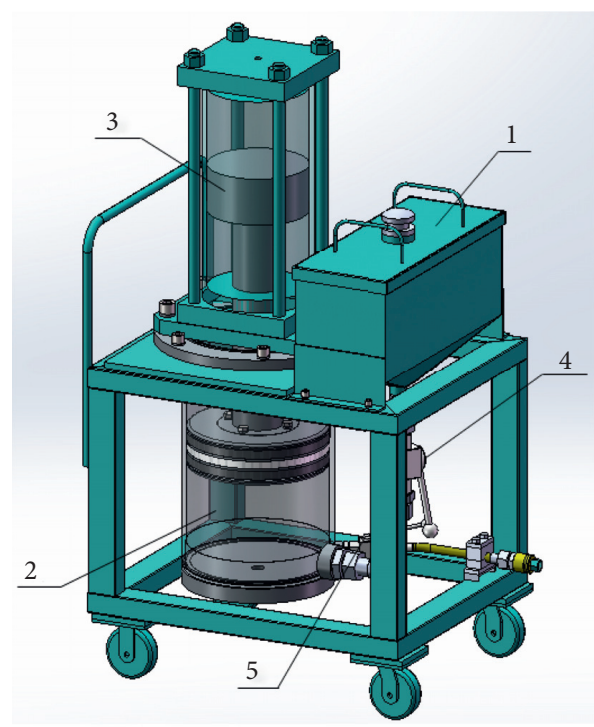

FIgURE 4: Slurry device. 1, storage silo; 2, syringe; 3, cylinder; 4, ball valve; 5, drain pipe.

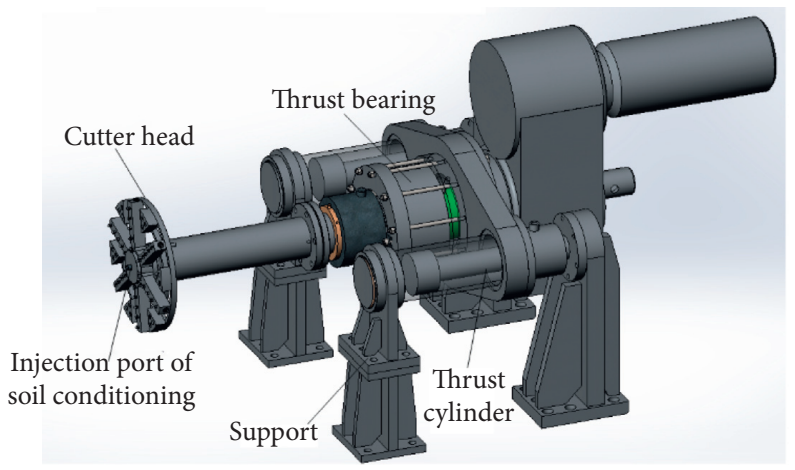

Figure 5: Propulsion and cutting system.

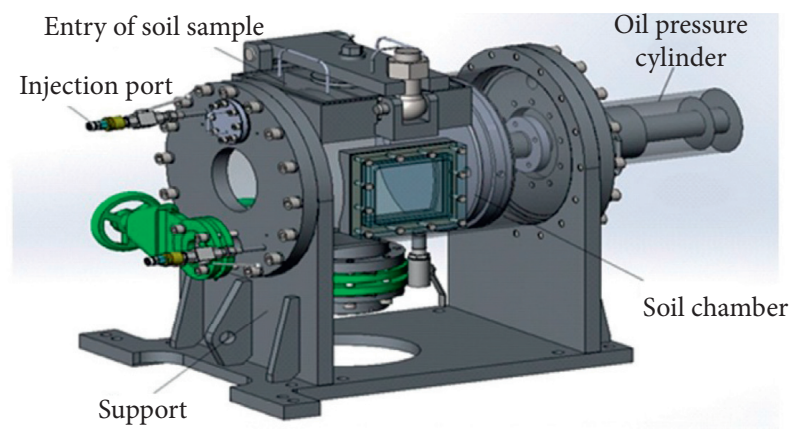

Figure 6: Soil chamber system.

2.3. Main Device. The main device is composed of a propulsion system, cutter head, and soil chamber system used to simulate the driving process of EPB shield machine (Figures 5 and 6). The external dimension is 3.1 meters long, 1.2 meters wide, and 1.2 meters high. The response data from the main device are automatically recorded to assess the performance of cutter head under different soil conditioning situations. Firstly, the soil sample in the soil chamber is pressurized to a required value equivalent to the target ground pressure. By regulating oil pressure cylinder and monitoring pressure gauge, the ground overload can also be taken into consideration. Then, the soil is cut using the cutter head driven by a propulsion system under a set advance rate and rotation speed. At the same time, soil conditioning materials are injected into the front of cutter head at a rate set by the foaming device and slurry device. The torque and thrust of cutter head, earth pressure, are automatically recorded in the driving process.

According to the similarity principles of scaled test, the cutter torque for actual shield machine can be determined by the simulation test as follows:

$$
T=\alpha k^{3} T_{0},
$$

where $T$ is the cutter torque of actual shield machine, $T_{0}$ is the cutter torque from the simulation test, $k$ is the similarity ratio of the cutter diameter between the test device and shield machine, and $\alpha$ is the calibration coefficient of the test system $(\alpha=1.1 \sim 1.3)$. 


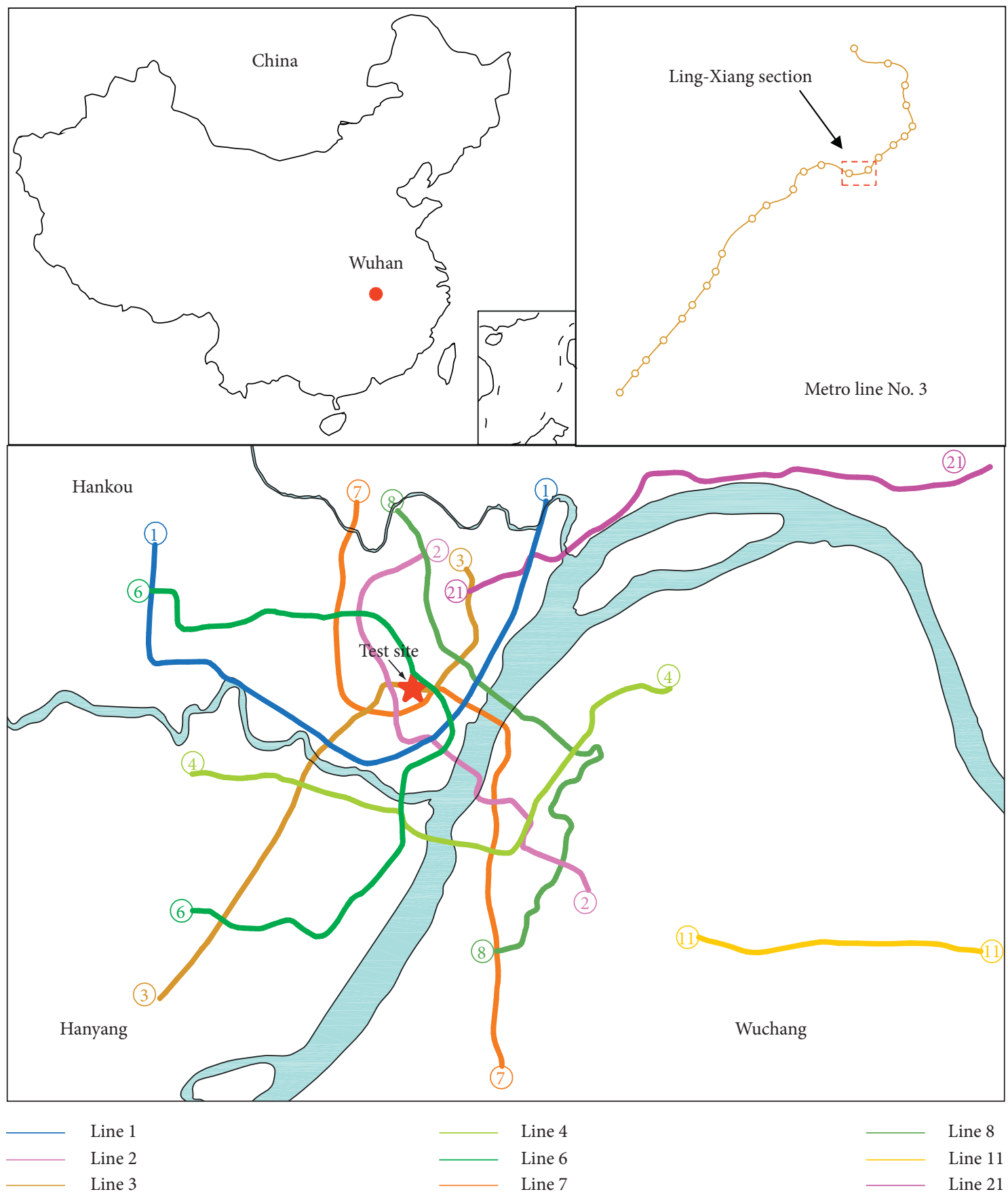

FIgURE 7: Metro lines of Wuhan city and the location of field test site.

\section{Material Preparation}

Material preparation involves as series of material tests on soil samples, foam, and slurry, which should be all prepared and optimized before the main test begin.

3.1. Soil. The soil samples for the test were silty sand taken from the tunnel site of Ling-Xiang tunnel section, of Wuhan Metro Line 3, which is $1200 \mathrm{~m}$, mainly located in silty sand, as shown in Figures 7-9. The natural moisture content of the silty sand ranges from $10 \%$ to $30 \%$ with internal friction angle of $30^{\circ}$, as shown in Table 1 . The silty sand from the tunnel site was remixed with water and reconsolidated to be the same moisture content and friction angle as its natural state in the pressurized soil chamber. The processing steps begin with the air drying of the soil sample, then followed by grinding, sieving, mixing, sealing, and storing. Finally, the soil samples are layered compacted to achieve the required moisture content and density. Otherwise, considering the 


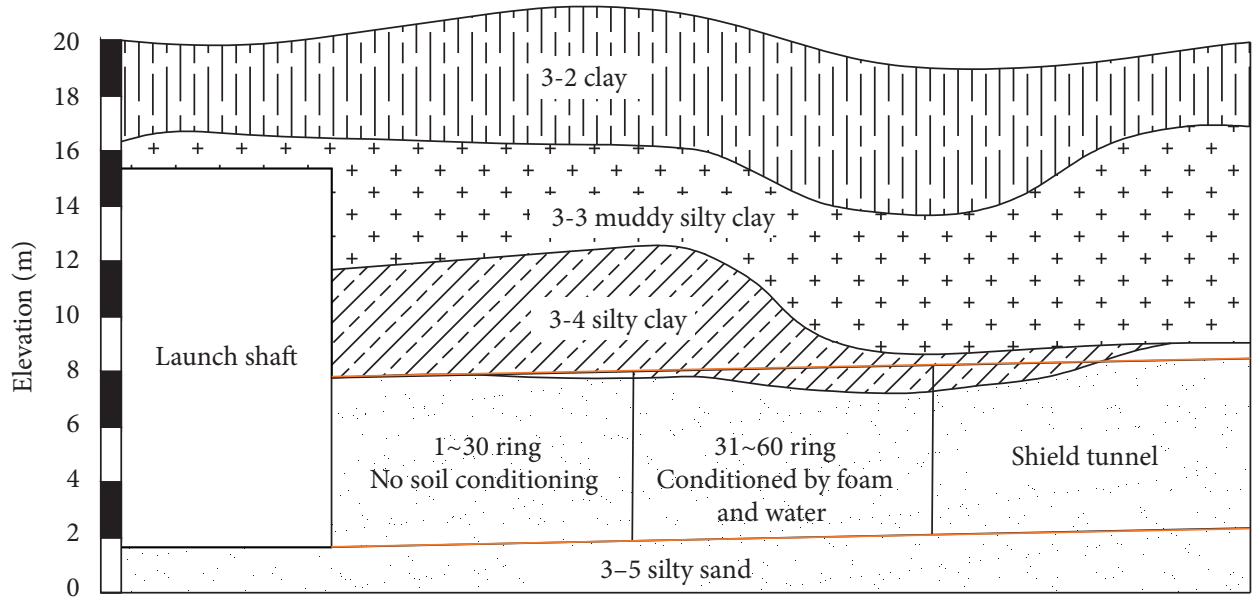

Figure 8: Geological profile of the experimental tunnel.

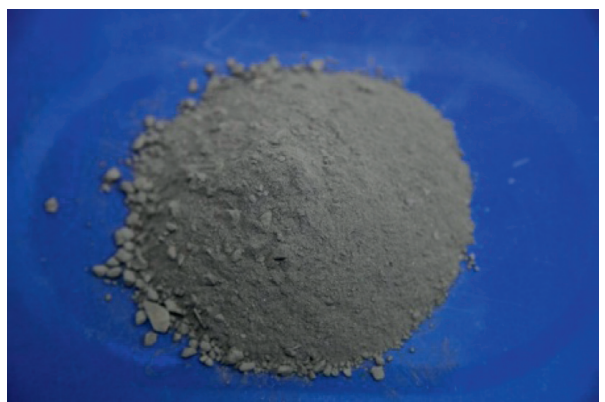

Figure 9: Test sample of silty sand from the tunnel site.

TABLe 1: Physical and mechanical parameters of soils.

\begin{tabular}{lcccccc}
\hline No. & Soil layers & $\gamma\left(\mathrm{kN} / \mathrm{m}^{3}\right)$ & $\omega(\%)$ & $c(\mathrm{kPa})$ & $\varphi\left(\left(^{\circ}\right)\right.$ & $E_{\mathrm{s}}(\mathrm{MPa})$ \\
\hline $3-2$ & Clay & 18.0 & 18.6 & 18 & 10 & 5.0 \\
$3-3$ & Muddy clay & 17.5 & 22.5 & 13 & 4 & 14 \\
$3-4$ & Silty clay & 18.0 & 29.2 & 0 & 3.0 \\
$3-5$ & Silty sand & 18.5 & 30.5 & 0 & 14 \\
\hline
\end{tabular}

Note. $\gamma$ is the unit weight; $\omega$ is the water content; $c$ is the cohesion; $\varphi$ is the friction angle; $E_{s}$ is the constrained modulus.

difference in mechanical property between original soil and remolded soil, the calibration coefficient $\alpha$ is adopted in equation (1). According to the natural particle grading curve of the silty sand (marked by red line in Figure 10), the recommended soil conditioning material for the soil is either foam or slurry $[49,50]$.

3.2. Foam. The foam conditioning material for shield tunneling is usually prepared by a foaming device to mix water with foaming agent, which is a surfactant that reduces surface tension of water to create the foam or increases its colloidal stability by inhibiting coalescence of bubbles. In order to find the best fit foaming and injection parameters for the silty sand, the foams were prepared by adjusting the foaming device to have a different foam expansion ratio $\left(\mathrm{F}_{\mathrm{er}}\right.$, see equation (2)) and foam stability $\left(F_{\mathrm{s}}\right.$, see equation (3)), which were described in detail by $\mathrm{Wu}$ et al. [51].
The recommended value of $F_{\mathrm{er}}$ for shield tunneling is 20-40:

$$
F_{e r}=\frac{V_{f}}{V_{l}},
$$

where $V_{f}$ is the volume of foam and $V_{l}$ is the volume of the foaming solution.

$F_{\mathrm{s}}$ can be measured by the foam dissipation test using the following equation:

$$
F_{s}=\frac{m_{d}}{m_{o}}
$$

where $m_{d}$ is the weight of the dissipated foam and $m_{o}$ is the initial weight of the foam. In shield tunneling practice, the weight of dissipated foam is changing over time, and thus, the half-dissipation time $\left(T_{1 / 2}\right)$ (i.e., the time during when $F_{\mathrm{s}}=0.5$ ) of foam is generally used to assess the stability of foam. The value ranges from $15-20 \mathrm{~min}$ for shield tunneling. 


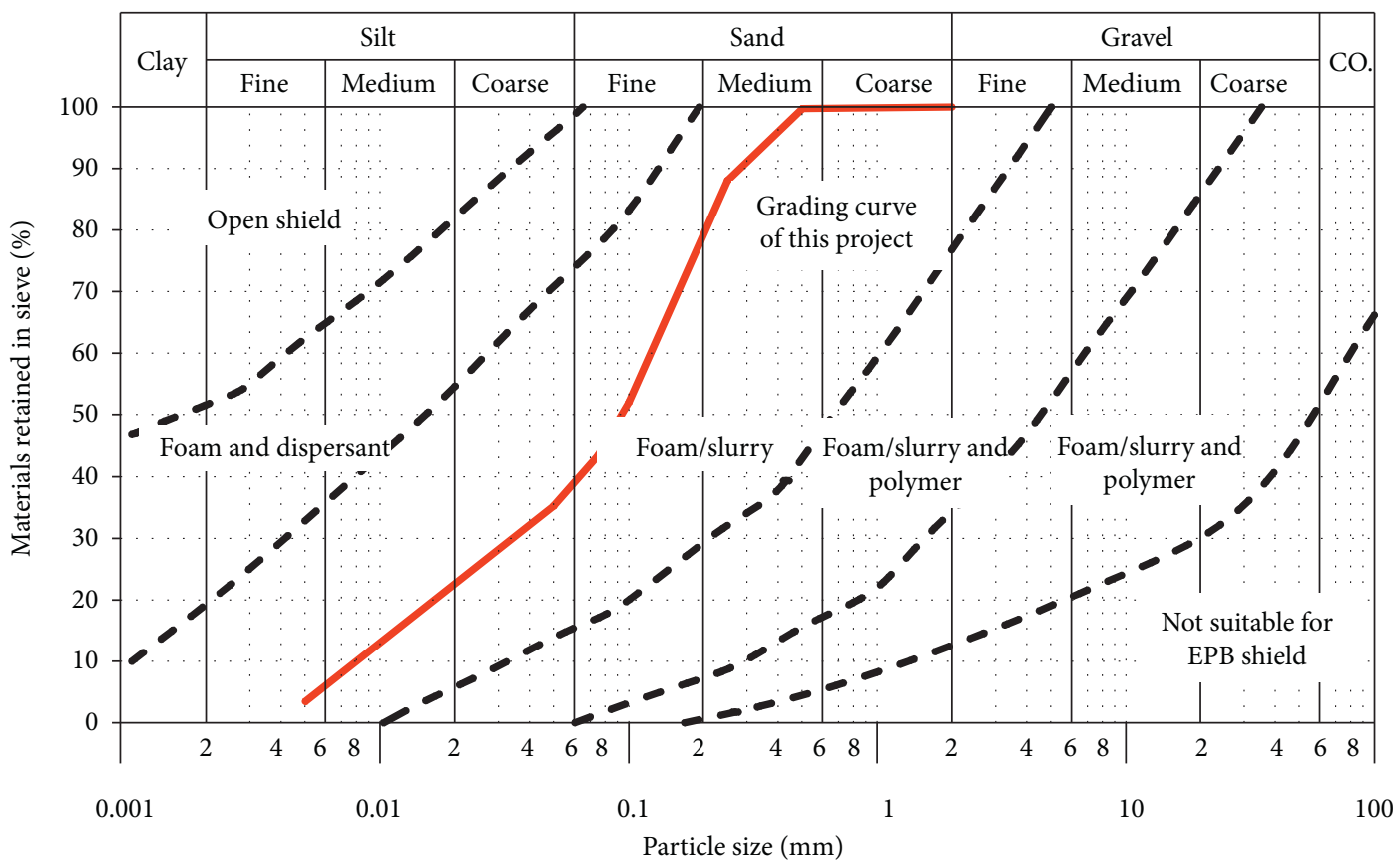

Figure 10: Particle grading curves of soils and suitable conditioning materials.

TABLE 2: Test levels and foaming parameters.

\begin{tabular}{|c|c|c|c|c|c|}
\hline Level & Concentration of foam solution (A) (\%) & Air pressure $(\mathrm{B})(\mathrm{MPa})$ & $\begin{array}{c}\text { Air flow }(\mathrm{C}) \\
(\mathrm{L} / \mathrm{min})\end{array}$ & Liquid pressure $(\mathrm{D})(\mathrm{MPa})$ & $\begin{array}{c}\text { Liquid flow (E) } \\
(\mathrm{mL} / \mathrm{min})\end{array}$ \\
\hline 1 & 2.0 & 0.2 & 1.0 & 0.2 & 50 \\
\hline 2 & 3.0 & 0.3 & 2.0 & 0.3 & 100 \\
\hline 3 & 4.0 & 0.4 & 3.0 & 0.4 & 150 \\
\hline 4 & 5.0 & 0.5 & 4.0 & 0.5 & 200 \\
\hline
\end{tabular}

TABLE 3: Scheme of orthogonal test.

\begin{tabular}{|c|c|c|c|c|c|c|c|c|c|c|}
\hline \multirow[t]{2}{*}{ No. } & \multicolumn{2}{|c|}{$\begin{array}{l}\text { Concentration of } \\
\text { foam solution (A) } \\
(\%)\end{array}$} & \multicolumn{2}{|c|}{$\begin{array}{l}\text { Air pressure }(\mathrm{B}) \\
(\mathrm{MPa})\end{array}$} & \multicolumn{2}{|c|}{$\begin{array}{l}\text { Air flow }(\mathrm{C}) \\
\quad(\mathrm{L} / \mathrm{min})\end{array}$} & \multicolumn{2}{|c|}{$\begin{array}{l}\text { Liquid pressure } \\
\text { (D) }(\mathrm{MPa})\end{array}$} & \multicolumn{2}{|c|}{$\begin{array}{l}\text { Liquid flow }(\mathrm{E}) \\
\quad(\mathrm{ml} / \mathrm{min})\end{array}$} \\
\hline & Level & Value & Level & Value & Level & Value & Level & Value & Level & Value \\
\hline 1 & 1 & 2.0 & 2 & 0.3 & 3 & 3.0 & 2 & 0.3 & 3 & 150 \\
\hline 2 & 3 & 4.0 & 4 & 0.5 & 1 & 1.0 & 2 & 0.3 & 2 & 100 \\
\hline 3 & 2 & 3.0 & 4 & 0.5 & 3 & 3.0 & 3 & 0.4 & 4 & 200 \\
\hline 4 & 4 & 5.0 & 2 & 0.3 & 1 & 1.0 & 3 & 0.4 & 1 & 50 \\
\hline 5 & 1 & 2.0 & 3 & 0.4 & 1 & 1.0 & 4 & 0.5 & 4 & 200 \\
\hline 6 & 3 & 4.0 & 1 & 0.2 & 3 & 3.0 & 4 & 0.5 & 1 & 50 \\
\hline 7 & 2 & 3.0 & 1 & 0.2 & 1 & 1.0 & 1 & 0.2 & 3 & 150 \\
\hline 8 & 4 & 5.0 & 3 & 0.4 & 3 & 3.0 & 1 & 0.2 & 2 & 100 \\
\hline 9 & 1 & 2.0 & 1 & 0.2 & 4 & 4.0 & 3 & 0.4 & 2 & 100 \\
\hline 10 & 3 & 4.0 & 3 & 0.4 & 2 & 2.0 & 3 & 0.4 & 3 & 150 \\
\hline 11 & 2 & 3.0 & 3 & 0.4 & 4 & 4.0 & 2 & 0.3 & 1 & 50 \\
\hline 12 & 4 & 5.0 & 1 & 0.2 & 2 & 2.0 & 2 & 0.3 & 4 & 200 \\
\hline 13 & 1 & 2.0 & 4 & 0.5 & 2 & 2.0 & 1 & 0.2 & 1 & 50 \\
\hline 14 & 3 & 4.0 & 2 & 0.3 & 4 & 4.0 & 1 & 0.2 & 4 & 200 \\
\hline 15 & 2 & 3.0 & 2 & 0.3 & 2 & 2.0 & 4 & 0.5 & 2 & 100 \\
\hline 16 & 4 & 5.0 & 4 & 0.5 & 4 & 4.0 & 4 & 0.5 & 3 & 150 \\
\hline
\end{tabular}

In practice, the $F_{e r}$ and $T_{1 / 2}$ are greatly influenced by concentration of the foam solution, air flow, liquid flow, air pressure, and liquid pressure. Considering the complex influences of these five factors, the multivariable tests (orthogonal tests of 4 levels and 5 variables) were performed firstly to determine the possible set of optimal foaming parameters, with test conditions shown in Tables 2 and 3 . And then, single-variable tests were 


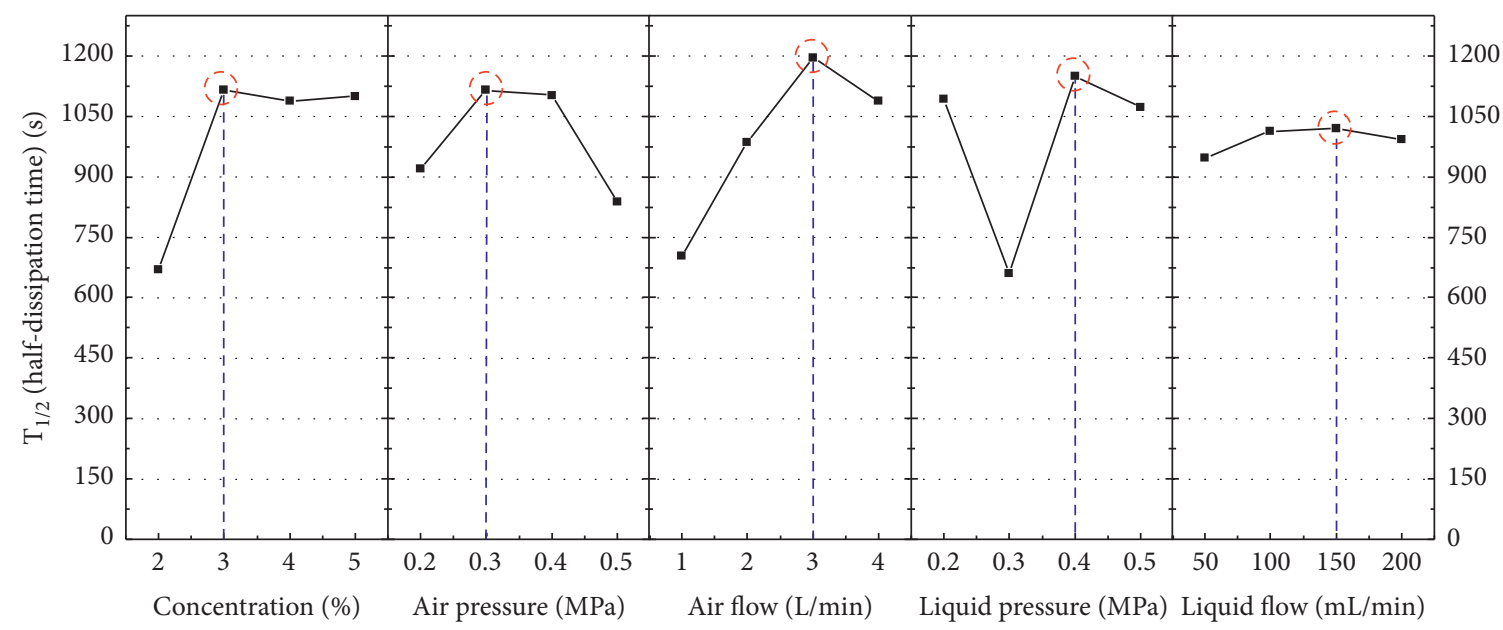

FIGURE 11: Effect of foaming parameters on half-dissipation time.

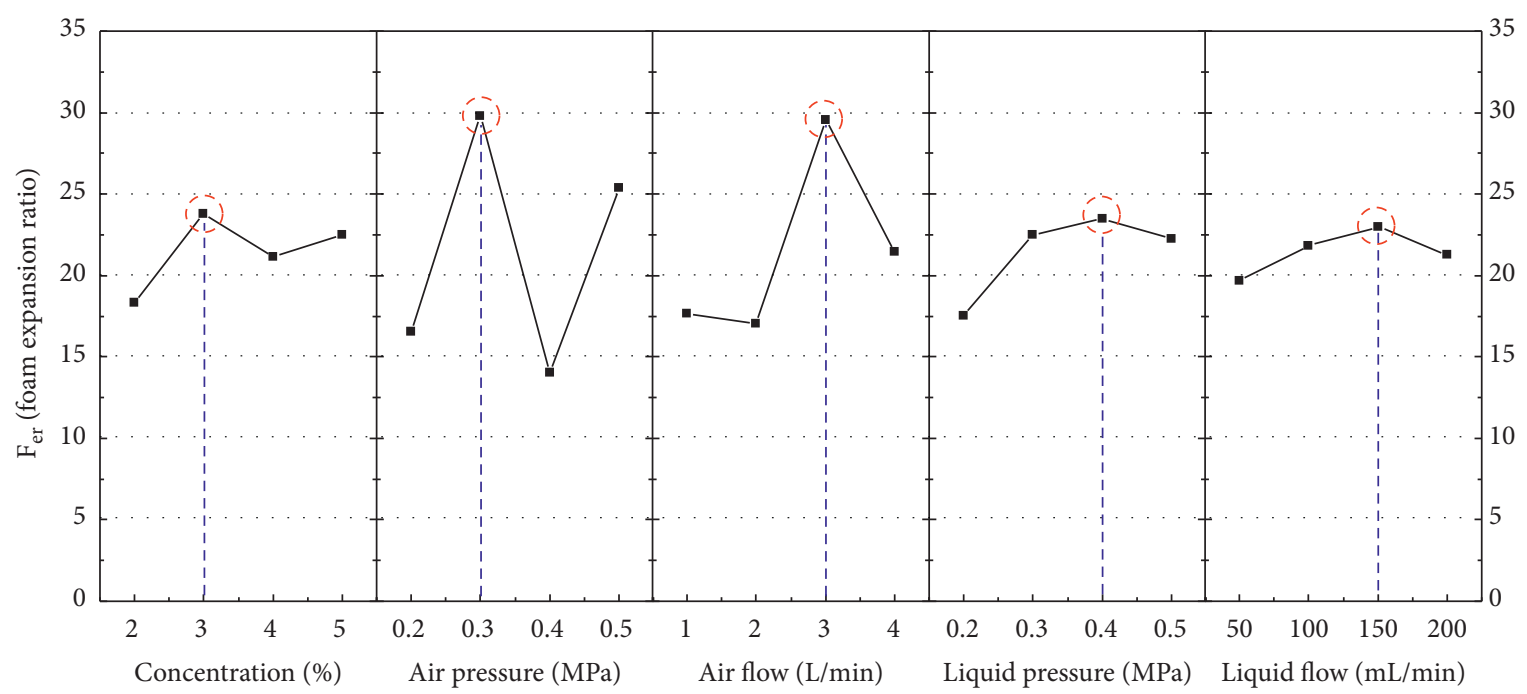

FIGURE 12: Effect of foaming parameters on foam expansion ratio.

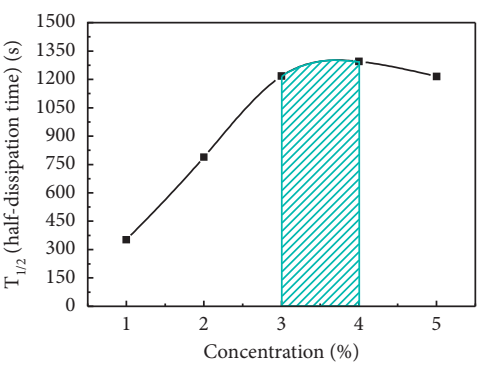

(a)

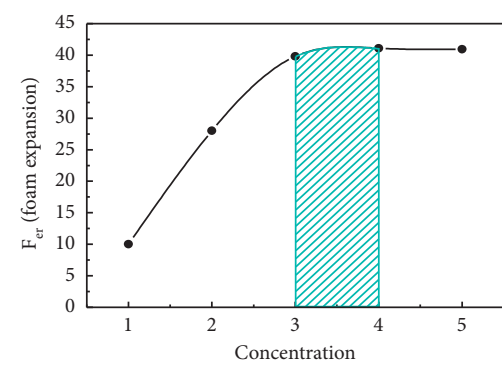

(b)

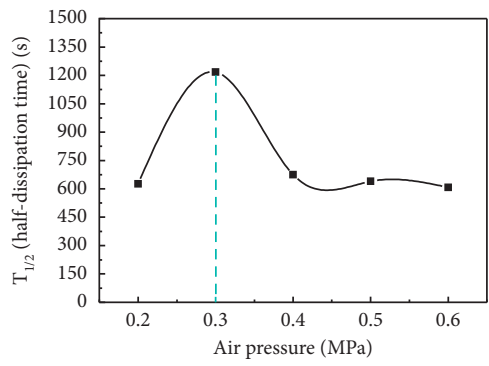

(c)

Figure 13: Continued. 


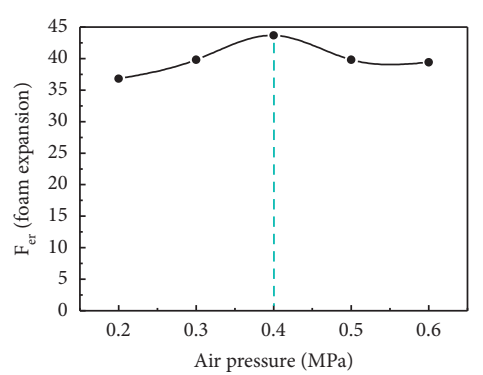

(d)

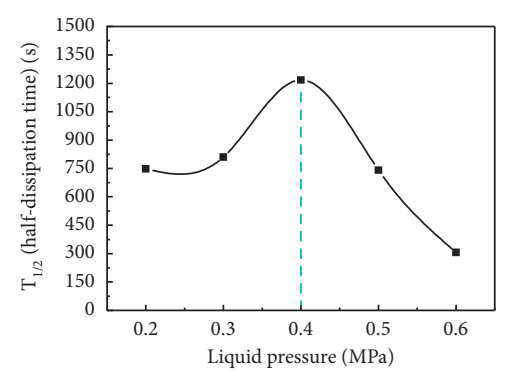

(g)

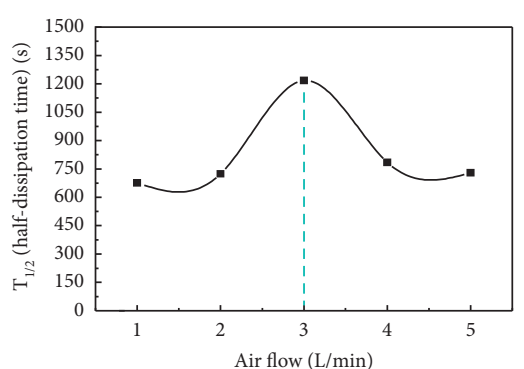

(e)

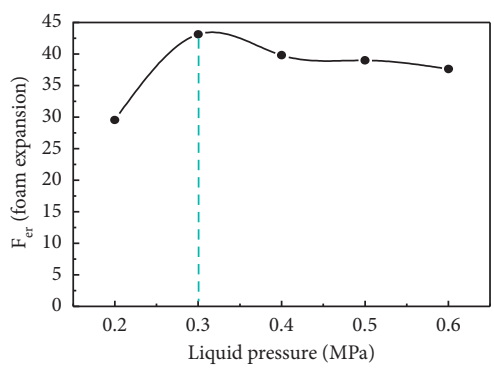

(h)

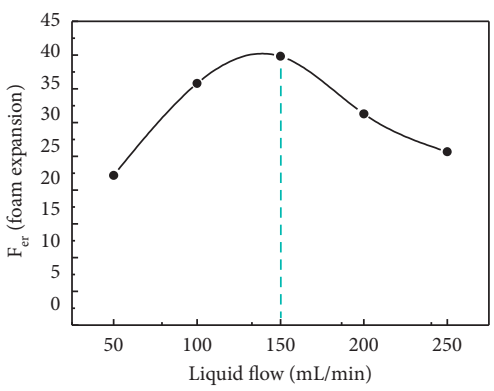

(j)

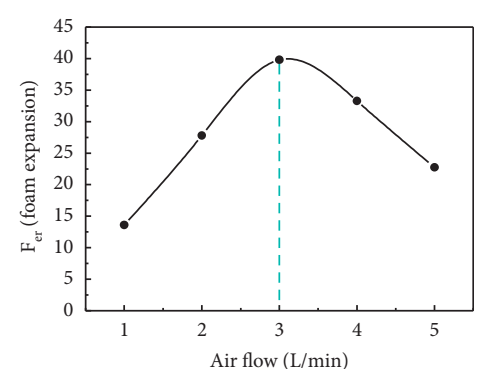

(f)

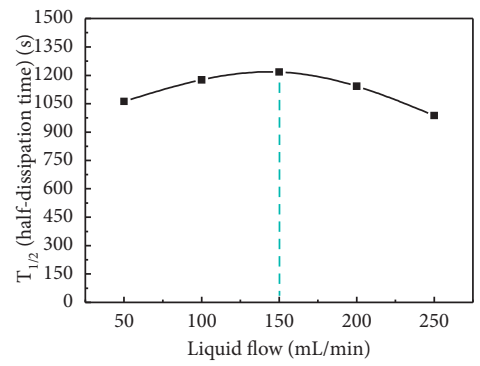

(i)

FIGURE 13: Effect of foaming parameters on foam properties.

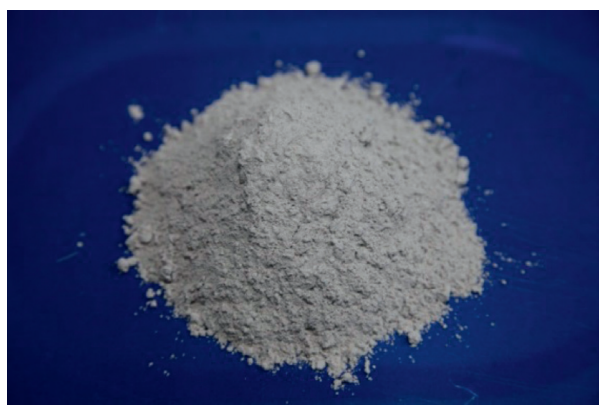

FIgURE 14: Bentonite.

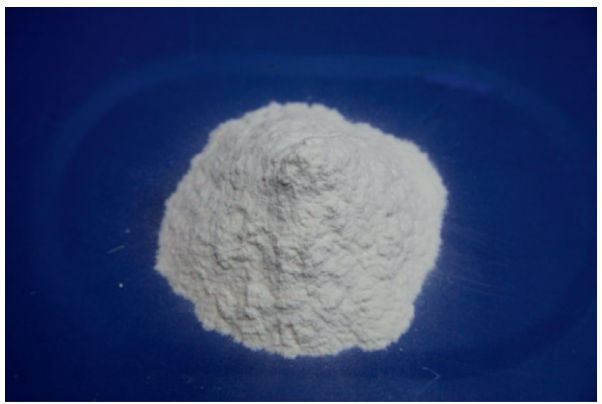

Figure 15: Carboxyl methyl cellulose (CMC). 
TABLE 4: Results of slurry optimization experiment.

\begin{tabular}{|c|c|c|c|c|c|c|c|c|}
\hline \multirow{2}{*}{ Type } & \multirow{2}{*}{ No. } & \multirow{2}{*}{$\begin{array}{c}\text { Water } \\
(\mathrm{g})\end{array}$} & \multicolumn{2}{|c|}{ Bentonite } & \multicolumn{2}{|c|}{$\mathrm{CMC}$} & \multirow{2}{*}{$\begin{array}{l}\text { Density } \\
\left(\mathrm{g} / \mathrm{cm}^{3}\right)\end{array}$} & \multirow{2}{*}{$\begin{array}{c}\text { Viscosity } \\
\text { (s) }\end{array}$} \\
\hline & & & $(\%)$ & $(\mathrm{g})$ & $(\%)$ & $(\mathrm{g})$ & & \\
\hline \multirow{12}{*}{ Initial tests } & 1 & 4000 & 1 & 40 & 0 & 0 & 1.017 & 15.26 \\
\hline & 2 & 4000 & 2 & 80 & 0 & 0 & 1.022 & 15.63 \\
\hline & 3 & 4000 & 3 & 120 & 0 & 0 & 1.027 & 16.50 \\
\hline & 4 & 4000 & 4 & 160 & 0 & 0 & 1.032 & 17.61 \\
\hline & 5 & 4000 & 5 & 200 & 0 & 0 & 1.037 & 19.01 \\
\hline & 6 & 4000 & 6 & 240 & 0 & 0 & 1.044 & 22.81 \\
\hline & 7 & 4000 & 7 & 280 & 0 & 0 & 1.048 & 27.96 \\
\hline & 8 & 4000 & 8 & 320 & 0 & 0 & 1.053 & 32.81 \\
\hline & 9 & 4000 & 9 & 360 & 0 & 0 & 1.059 & 49.96 \\
\hline & 10 & 4000 & 10 & 400 & 0 & 0 & 1.063 & 77.23 \\
\hline & 11 & 4000 & 11 & 440 & 0 & 0 & 1.071 & 138.56 \\
\hline & 12 & 4000 & 12 & 480 & 0 & 0 & 1.074 & 238.00 \\
\hline \multirow{12}{*}{ Combination tests } & 13 & 4000 & 5 & 200 & 0.15 & 0.3 & 1.036 & 22.73 \\
\hline & 14 & 4000 & 5 & 200 & 0.3 & 0.6 & 1.037 & 23.88 \\
\hline & 15 & 4000 & 5 & 200 & 0.5 & 1 & 1.036 & 25.54 \\
\hline & 16 & 4000 & 5 & 200 & 0.7 & 1.4 & 1.037 & 30.58 \\
\hline & 17 & 4000 & 8 & 320 & 0.15 & 0.48 & 1.056 & 47.46 \\
\hline & 18 & 4000 & 8 & 320 & 0.3 & 0.96 & 1.062 & 59.46 \\
\hline & 19 & 4000 & 8 & 320 & 0.5 & 1.6 & 1.054 & 79.36 \\
\hline & 20 & 4000 & 8 & 320 & 0.7 & 2.24 & 1.062 & 117.43 \\
\hline & 21 & 4000 & 10 & 400 & 0.15 & 0.6 & 1.062 & 88.18 \\
\hline & 22 & 4000 & 10 & 400 & 0.3 & 1.2 & 1.071 & 133.30 \\
\hline & 23 & 4000 & 10 & 400 & 0.5 & 2 & 1.072 & 185.30 \\
\hline & 24 & 4000 & 10 & 400 & 0.7 & 2.8 & 1.071 & 245.60 \\
\hline
\end{tabular}

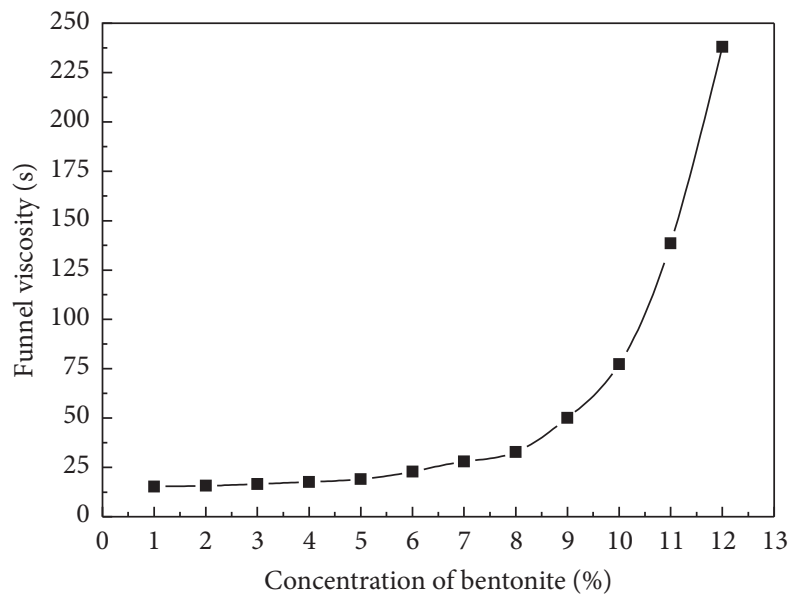

FIGURE 16: Effect of bentonite concentration on funnel viscosity.

performed further to verify and confirm the foaming parameters.

According to the multivariable test results shown in Figures 11 and 12, the possible set of optimal foaming parameters is $3.0 \%$ foam solution concentration, $3.0 \mathrm{~L} / \mathrm{min}$ air flow, $150 \mathrm{~mL} / \mathrm{min}$ liquid flow, $0.3 \mathrm{MPa}$ air pressure, and $0.4 \mathrm{MPa}$ liquid pressure. To further verify and amend the results of multivariable test, the single-variable tests are conducted, and the results are summarized in Figure 13. As shown in Figures 13(a) and 13(b), when the concentration of foam solution increases to $3 \%$, the half-dissipation time and expansion ratio nearly reach the maximum values of
$1200 \mathrm{~s}$ and 40 , respectively. Figure 13(c) illustrates that the foam has the best stability when the air pressure is $0.3 \mathrm{MPa}$, and the expansion ratio is controlled in 20-40 (see Figure 13(d)). Figures 13(e) and 13(f) show the relationship between the foam properties and air flow; the preferred air flow is $3 \mathrm{~L} / \mathrm{min}$. Additionally, the liquid pressure and liquid flow should be $0.4 \mathrm{MPa}$ and $150 \mathrm{~mL} / \mathrm{min}$, respectively, as shown in Figures 13(g)-13(j). Hence, the optimized foaming parameters were confirmed as follows: $3.0 \%$ foam solution concentration, $3.0 \mathrm{~L} / \mathrm{min}$ air flow, $150 \mathrm{~mL} / \mathrm{min}$ liquid flow, $0.3 \mathrm{MPa}$ air pressure, and $0.4 \mathrm{MPa}$ liquid pressure. The corresponding half-dissipation time and the 


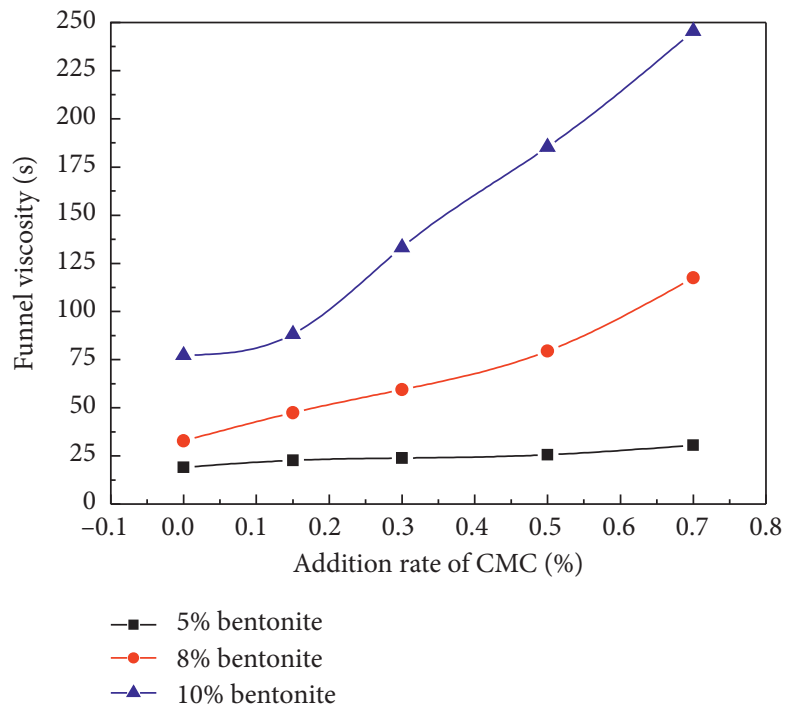

Figure 17: Effect of addition rate of CMC on funnel viscosity.

TABLE 5: Testing conditions for soil conditioning.

\begin{tabular}{lcccc}
\hline No. & Soil pressure $(\mathrm{MPa})$ & Water content $(\%)$ & Soil conditioner & Injection ratio of volume \\
\hline 1 & 0.1 & 10 & Foam & $0-100 \%$ \\
2 & 0.1 & 10 & Slurry & $0-30 \%$ \\
3 & 0.1 & 30 & Foam & $0-100 \%$ \\
4 & 0.1 & 30 & Slurry & $0-30 \%$ \\
5 & 0.25 & 10 & Foam & $0-100 \%$ \\
6 & 0.25 & 10 & Slurry & $0-30 \%$ \\
7 & 0.25 & 30 & Foam & $0-100 \%$ \\
8 & 0.25 & 30 & Slurry & $0-30 \%$ \\
\hline
\end{tabular}

TABLE 6: Relationship between foam injection ratio and advance distance.

\begin{tabular}{lcccccc}
\hline Advance distance $(\mathrm{mm})$ & $0-30$ & $31-60$ & $61-90$ & $91-120$ & $121-150$ & $151-180$ \\
\hline Injection ratio $(\%)$ & 0 & $10-15$ & $30-35$ & $50-55$ & $70-75$ & $90-100$ \\
\hline
\end{tabular}

TABLE 7: Relationship between slurry injection ratio and advance distance.

\begin{tabular}{|c|c|c|c|c|c|c|c|c|}
\hline Advance distance $(\mathrm{mm})$ & $0-30$ & $31-60$ & $61-90$ & $91-120$ & $121-150$ & $151-180$ & $181-210$ & $211-240$ \\
\hline Injection ratio (\%) & 0 & $3-5$ & $7-8$ & $10-12$ & $14-16$ & $18-20$ & $24-26$ & $28-30$ \\
\hline
\end{tabular}

TAвLE 8: Driving parameters of shield cutter head.

\begin{tabular}{lcc}
\hline Opening ratio (\%) & Rotating speed & Advance speed \\
\hline 50 & $1 \mathrm{r} / \mathrm{min}$ & $30 \mathrm{~mm} / \mathrm{min}$ \\
\hline
\end{tabular}

foam expansion ratio are recommended as $1217 \mathrm{~s}$ and 39.81 , respectively.

3.3. Bentonite Slurry and CMC. The other conditioning material for the test is the bentonite with addition of carboxyl methyl cellulose (CMC, $\left[\mathrm{C}_{6} \mathrm{H}_{7} \mathrm{O}_{2}(\mathrm{OH})_{2} \mathrm{CH}_{2} \mathrm{COO}\right.$ $\mathrm{Na}]_{\mathrm{n}}$ ) which can significantly increase the viscosity of bentonite slurry as thickener when it is dissolved in water. The influences of the bentonite (Figure 14) and CMC
(Figure 15) concentration were investigated via an optimization experiment of the slurry properties (density and funnel viscosity) (Table 4). In the 12 initial try tests shown in the table, only the concentration of bentonite was adjusted, and the results show that the funnel viscosity is more sensitive to the bentonite concentration than the density. As shown in Figure 16, the funnel viscosity increases with the bentonite concentration. When the concentration reaches $11 \%$, the viscosity increases sharply and part of bentonite tends to be insoluble in water. To maintain the viscosity 


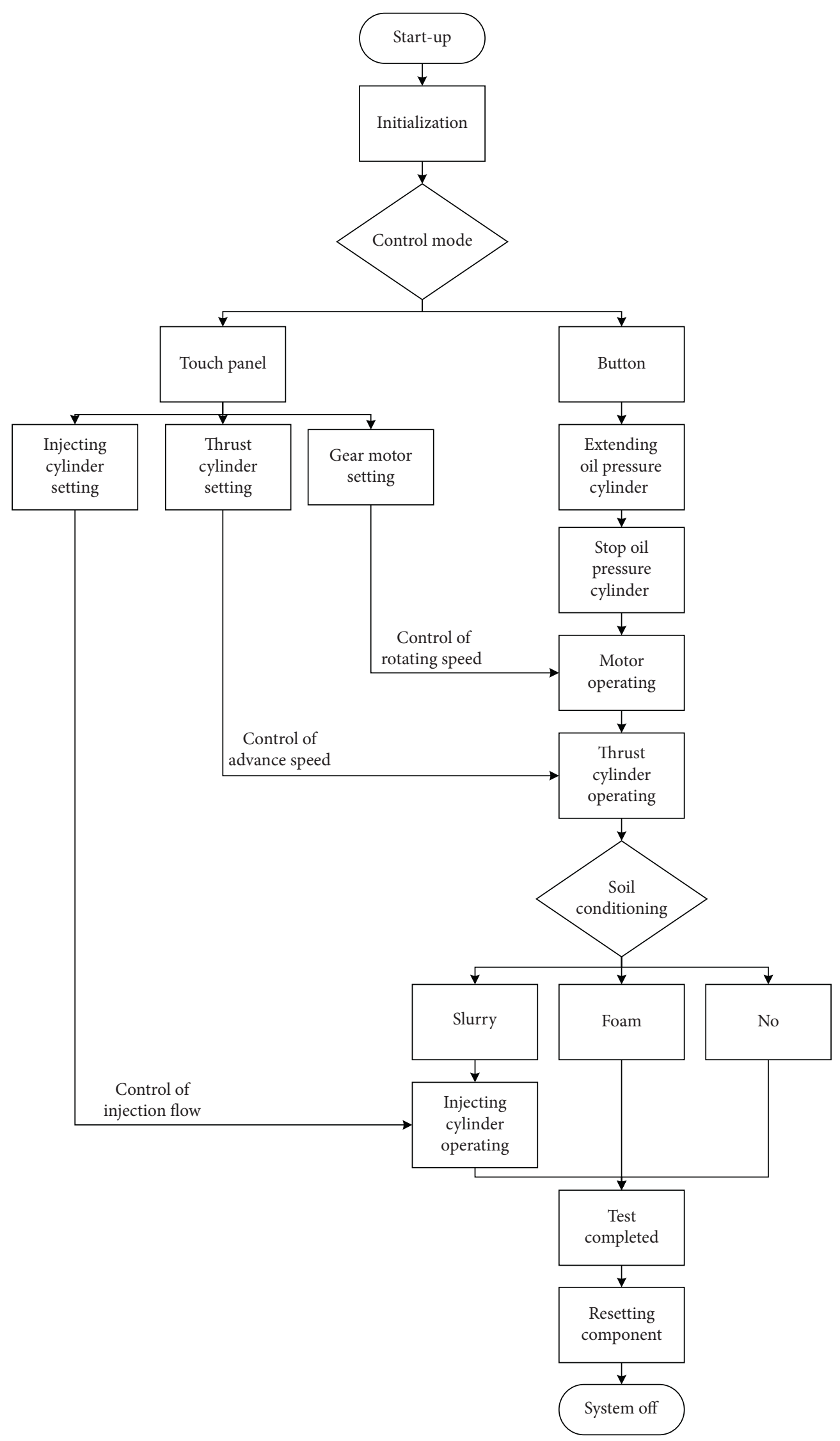

FIgURE 18: The testing process. 


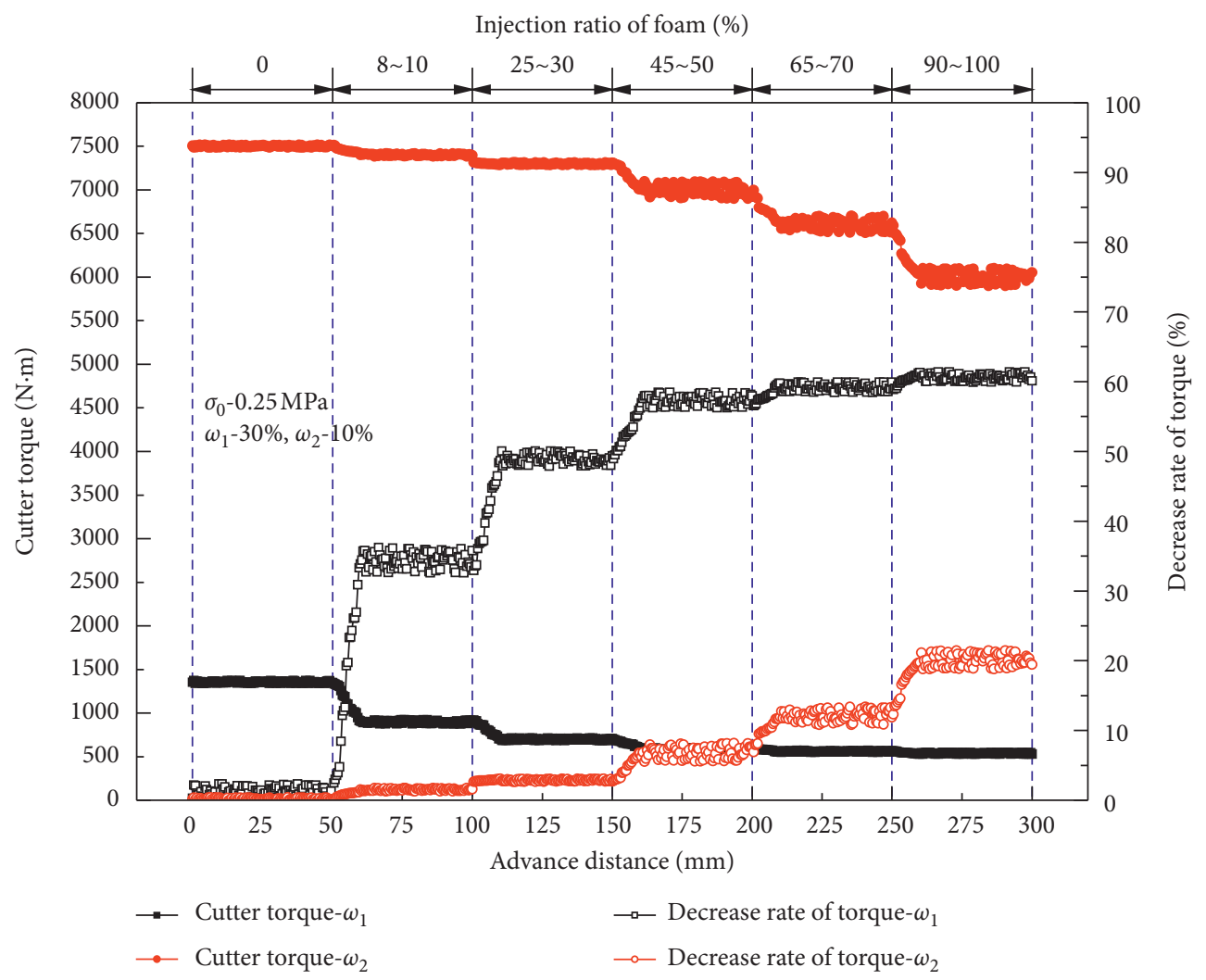

FIGURE 19: Effect of foam conditioning and soil water contents on cutter torque at soil pressure $0.25 \mathrm{MPa}$.

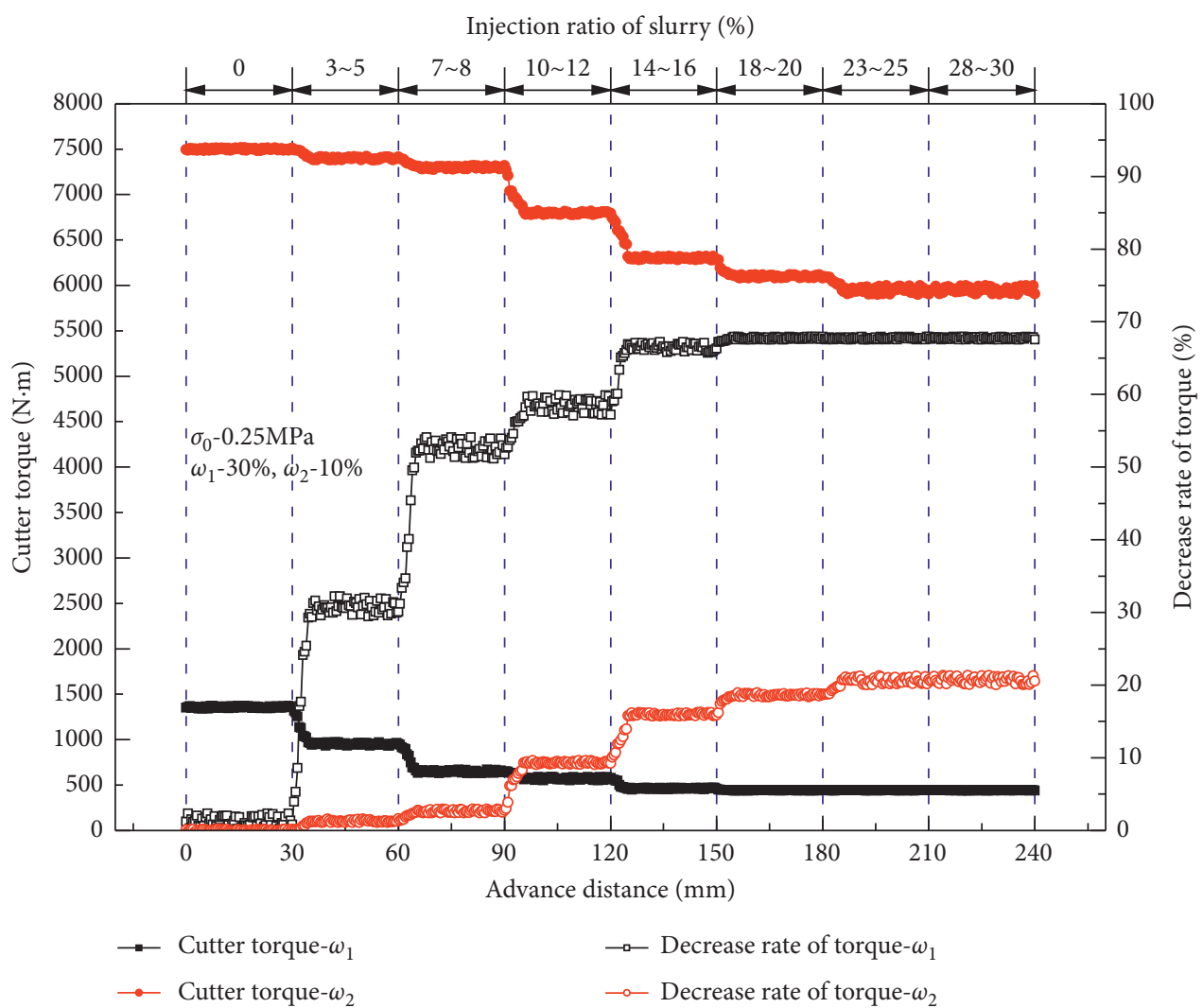

FiguRE 20: Effect of slurry conditioning and soil water contents on cutter torque at soil pressure $0.25 \mathrm{MPa}$. 


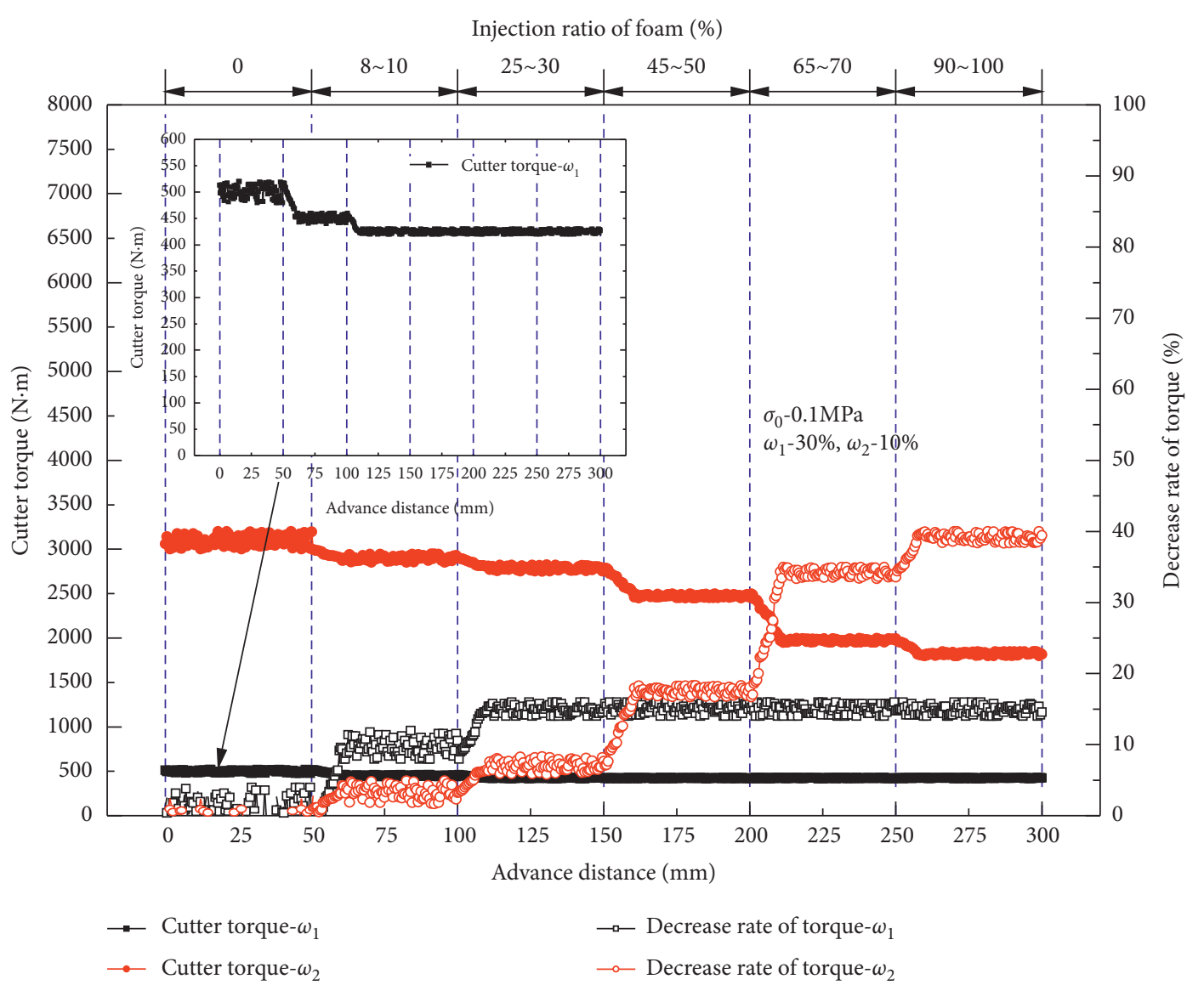

FIGURE 21: Effect of foam conditioning and soil water contents on cutter torque at soil pressure $0.1 \mathrm{MPa}$.

between 60 and $80 \mathrm{~s}$, which is suitable for this type of ground, bentonite concentrations of $5 \%, 8 \%$, and $10 \%$ are mixed with CMC (test no. 13 to test no. 24 in Table 4). According to Figure 17, the addition rate of CMC has an obvious effect on the funnel viscosity for bentonite concentrations of $8 \%$ and $10 \%$. Hence, part of bentonite can be replaced with CMC to improve the solubility of the slurry. The recommended slurry proportioning is $8 \%$ bentonite and $0.5 \% \mathrm{CMC}$, resulting in a density and funnel viscosity of $1.054 \mathrm{~g} / \mathrm{cm}^{3}$ and $79.36 \mathrm{~s}$, respectively.

\section{Main Test}

4.1. Test Procedure. The testing conditions and parameters are shown in Tables 5-7. The soil samples were configured with two moisture contents of $10 \%$ and $30 \%$ and then pressurized at $0.1 \mathrm{MPa}$ and $0.25 \mathrm{MPa}$, respectively. Based on the abovementioned optimized parameters of foam and slurry, the injection process was performed in several stages with different injection ratios, as shown in Tables 6 and 7. The driving parameters of the shield cutter head were set, as shown in Table 8 , in compliance with the onsite construction parameters of shield. During the test process, the cutter torque was automatically recorded by the torque sensor installed on the ground suitability test system. The cutter torque is regarded as a comprehensive index in the test for accessing the cutting performance because the changes in cutter torque closely reflect the abrasion of cutters and cutting efficiency. The process of testing is shown in Figure 18.

4.2. Test Results. According to the above test procedure, the influences of the moisture content and confining pressure of soil, the conditioner type, and the injection ratio on the cutting performance were experimentally investigated, respectively, and summarized below.

4.2.1. The Effect of Moisture Content of Silt Sand. As shown in Figures 19-22, the moisture content of the silty sand affects significantly the cutting torque, which increased by 5 to 7 times when the moisture content increased from $10 \%$ to $30 \%$ in case of no soil conditioning. However, it was only when the foam injection ratio reached $30 \%$ or when the slurry injection ratio exceeded $5 \%$ that the cutter torque began to reduce remarkably.

The maximum reduction in the cutter torque was a result of combined effect of the moisture content and soil pressure. When the moisture content was $10 \%$ at a soil pressure of 


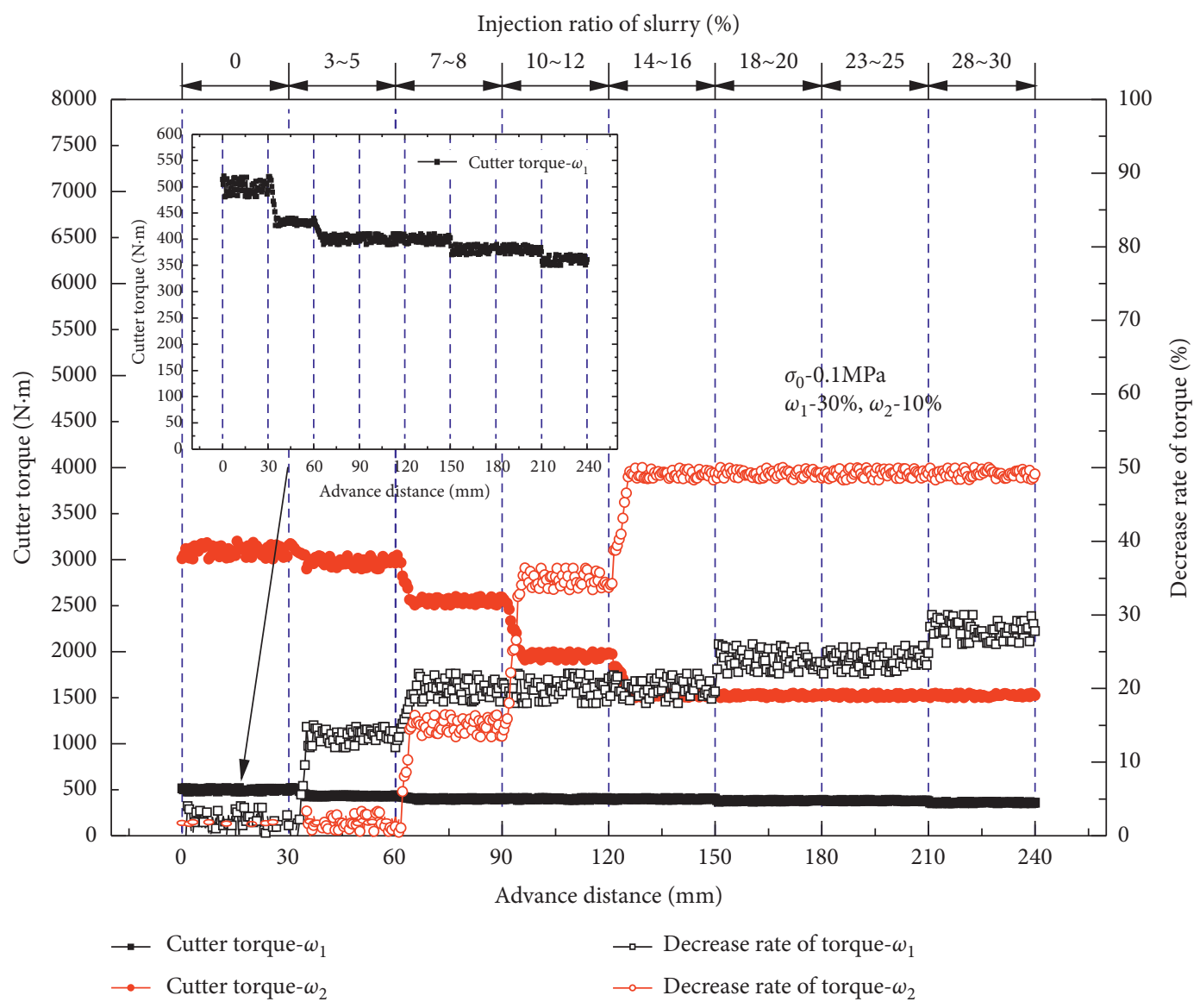

FIGURE 22: Effect of slurry conditioning and soil water contents on cutter torque at soil pressure $0.1 \mathrm{MPa}$.

$0.1 \mathrm{MPa}$, the maximum reduction ratio of cutter torque occurred as $40 \%-60 \%$, while at the same moisture content and higher pressure of $0.25 \mathrm{MPa}$, the maximum reduction in cutter torque was only $20 \%-30 \%$. However, the maximum reduction ratio could reach $60 \%-70 \%$ when the moisture content was $30 \%$ and soil pressure was $0.25 \mathrm{MPa}$.

4.2.2. The Effect of Confining Pressure. As shown in Figures 23-26, the cutter torque in silty sand is positively correlated with the soil confining pressure. When the soil confining pressure increased from $0.1 \mathrm{MPa}$ to $0.25 \mathrm{MPa}$, the cutter torque increased by 2 to 3 times in case of no soil conditioning.

When the soil moisture content was $30 \%$, even a high soil confining pressure could result in a larger decrease in the cutter torque with soil conditioning. For instance, a maximum decrease in the cutter torque of $60 \%$ could be obtained when the soil confining pressure was $0.25 \mathrm{MPa}$, while only a $15 \%$ decrease occurred when the soil confining pressure was $0.1 \mathrm{MPa}$, as shown in Figure 23.
However, the opposite was observed when the moisture content was $10 \%$. A higher soil pressure resulted in smaller decreases in the cutter torque with soil conditioning. However, the differences in the reduction of cutter torque under the two pressure conditions were close. As shown in Figure 24, the maximum reduction was only $1200-1500 \mathrm{~N} \mathrm{~m}$ under different soil pressures.

4.2.3. The Effect of Conditioning Material. The effect of different kinds of soil conditioners on the cutting performance was compared under the same moisture content and soil pressure conditions, as shown in Figures 27-30.

The results revealed that the effect of soil conditioning is limited when the injection ratio reaches a certain value. For example, Figure 27 shows that when the injection ratio of slurry exceeds $15 \%$ or that of foam exceeds $45 \%$, the decrease rate of the cutter torque tends to be stable.

Judging from the maximum decrease of the torque, slurry was a better option than foam for decreasing the cutter torque. In order to achieve the same effect of soil conditioning, the 


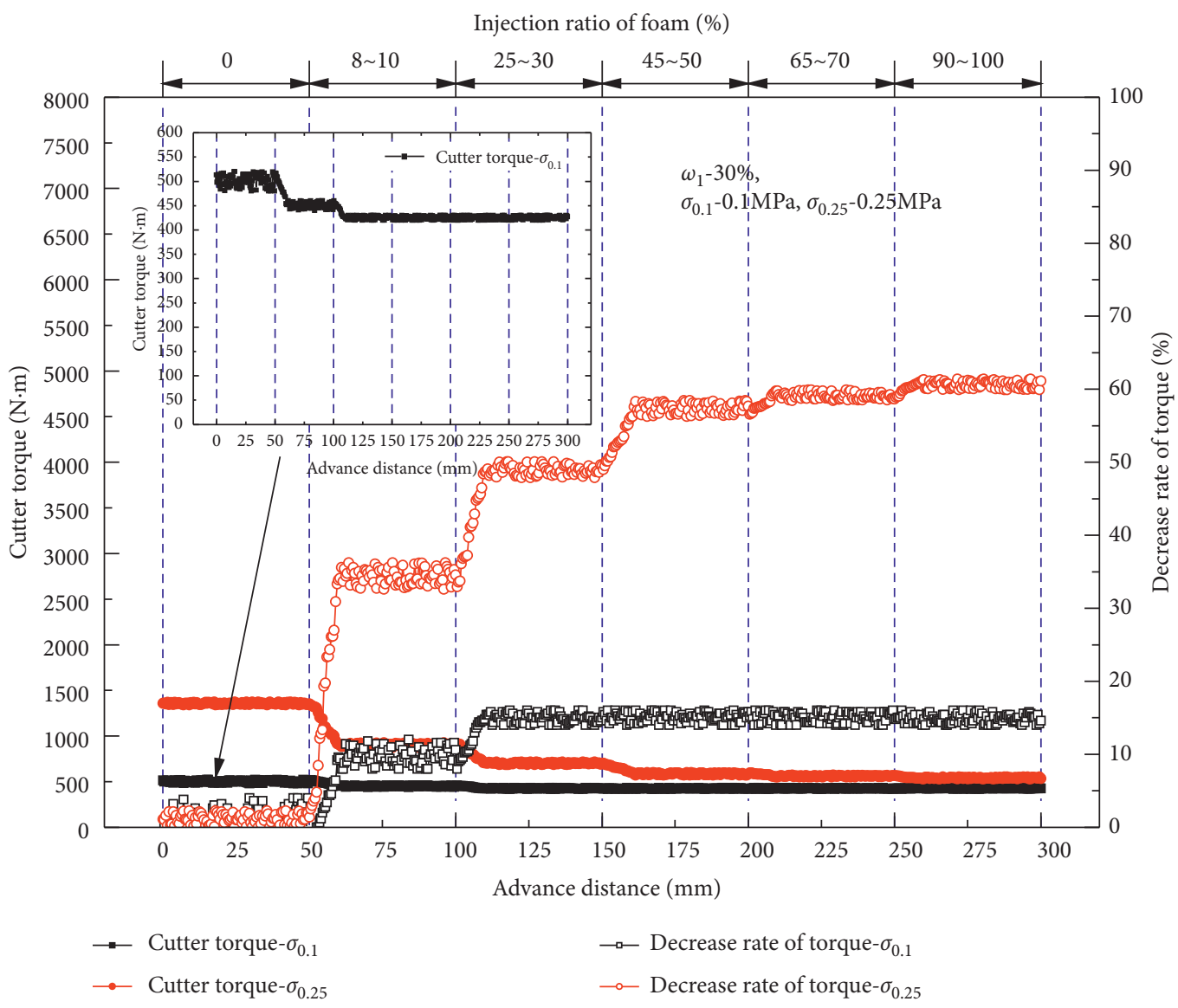

FIGURE 23: Effect of foam conditioning and soil pressure on cutter torque at water content $30 \%$.

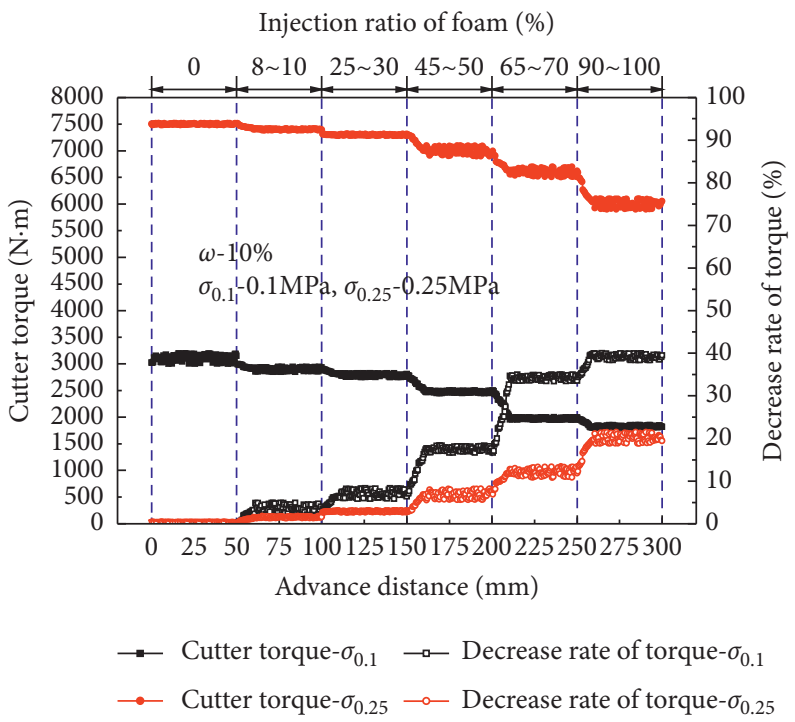

FIGURE 24: Effect of foam conditioning and soil pressure on cutter torque at water content $10 \%$. 
Injection ratio of slurry (\%)

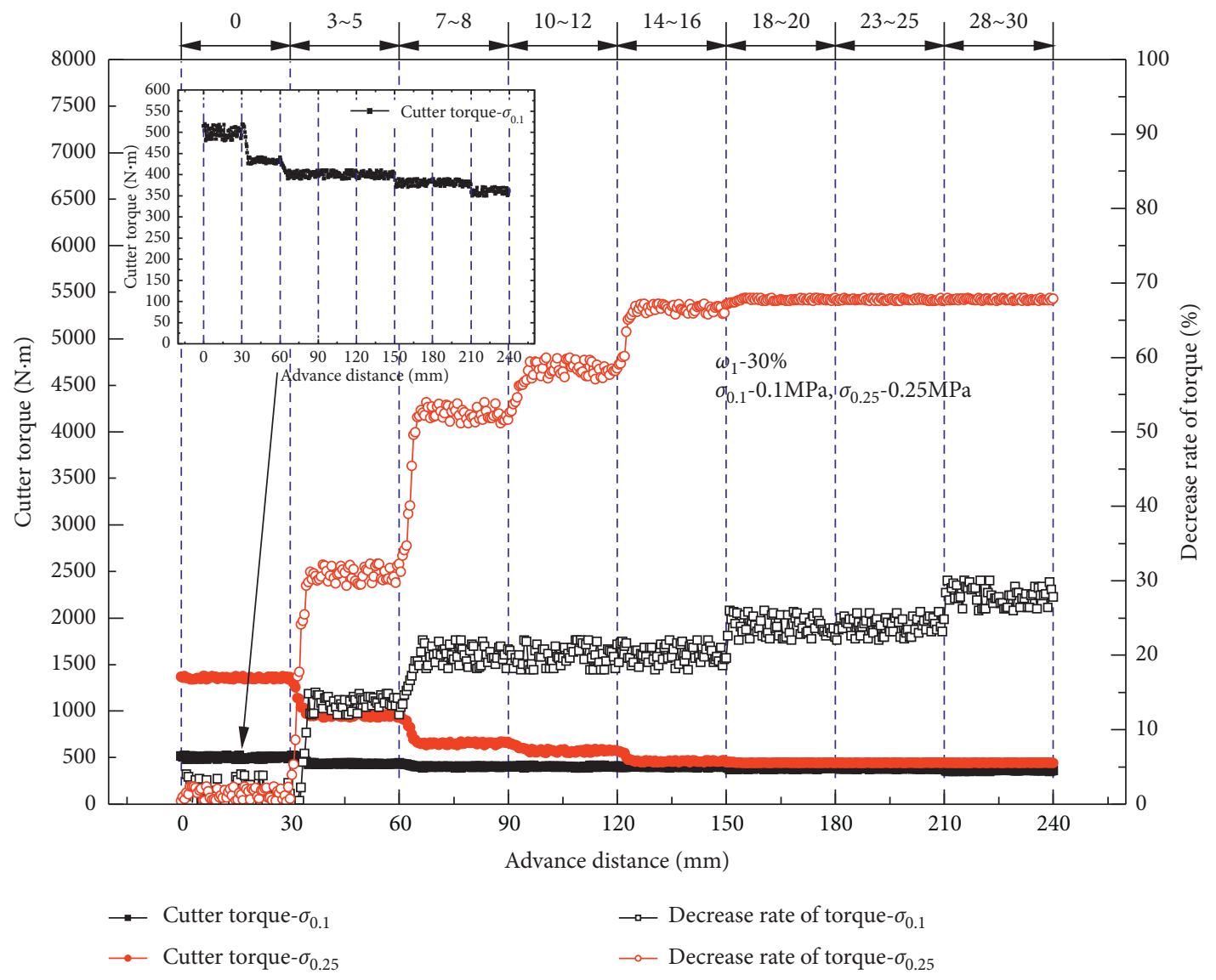

FIGURE 25: Effect of slurry conditioning and soil pressure on cutter torque at water content $30 \%$.

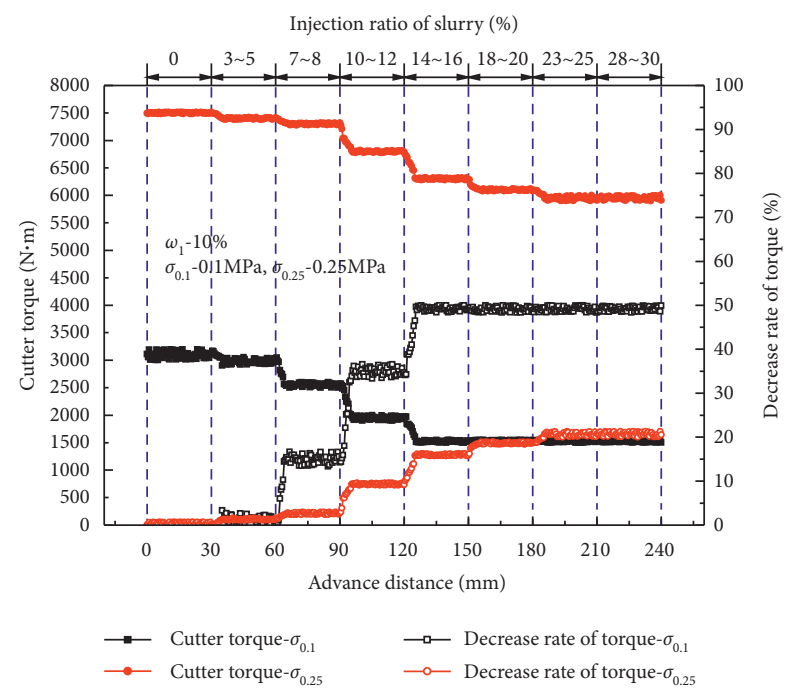

FIGURE 26: Effect of slurry conditioning and soil pressure on cutter torque at water content $10 \%$. 


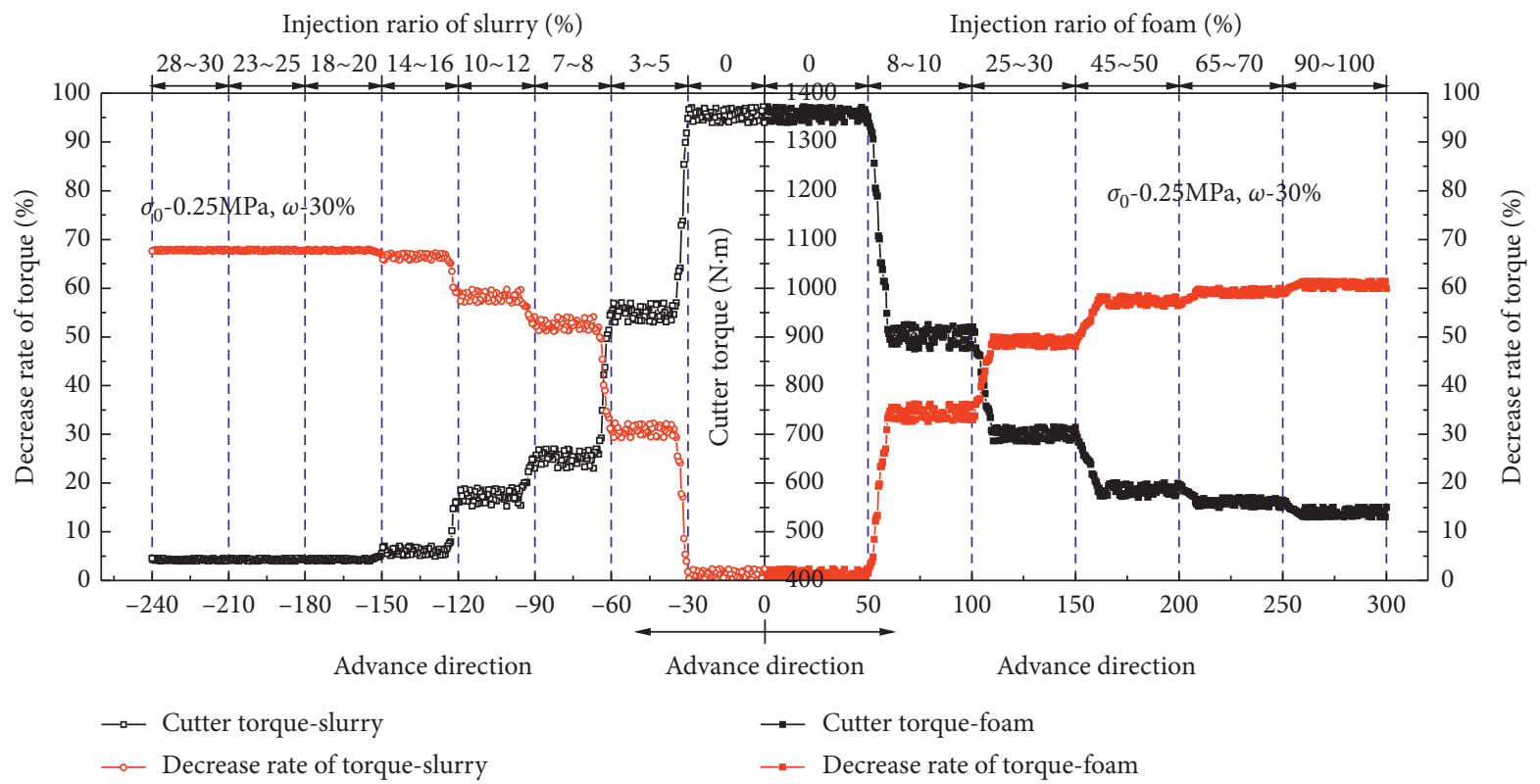

FIgURE 27: Effect of two types of soil conditioners on cutter torque at water content $30 \%$ and soil pressure $0.25 \mathrm{MPa}$.

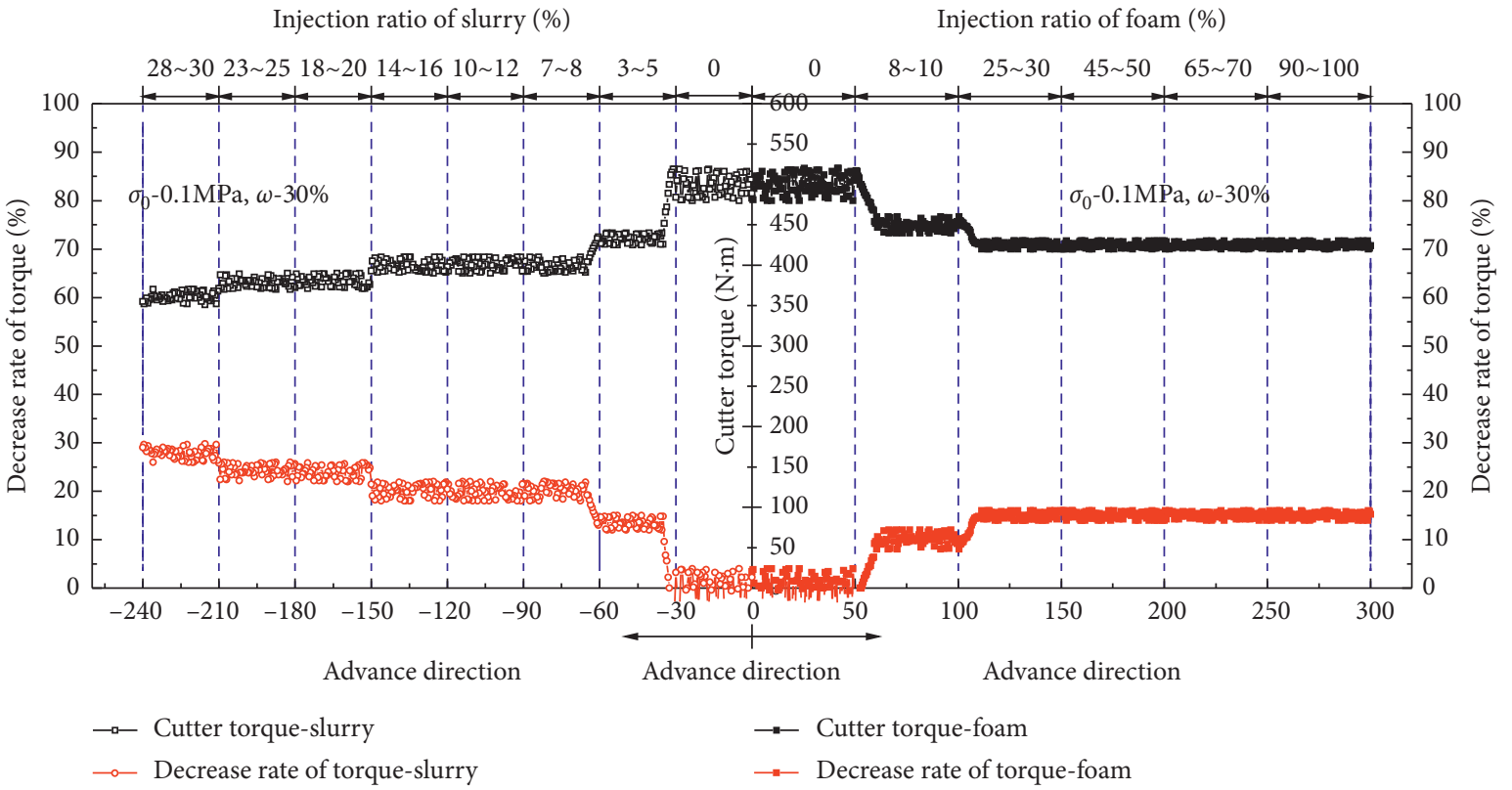

FIGURE 28: Effect of two types of soil conditioners on cutter torque at water content $30 \%$ and soil pressure $0.1 \mathrm{MPa}$.

injection ratios of the two types of soil conditioners were different. As shown in Figure 27, the injection ratios of foam and slurry should be $45 \%$ and $10 \%$, respectively, to achieve the same maximum reduction of torque at $60 \%$.

\section{Field Test and Verification}

To realize the onsite effect of soil conditioning on the cutting performance of the shield machine, a field experiment was 


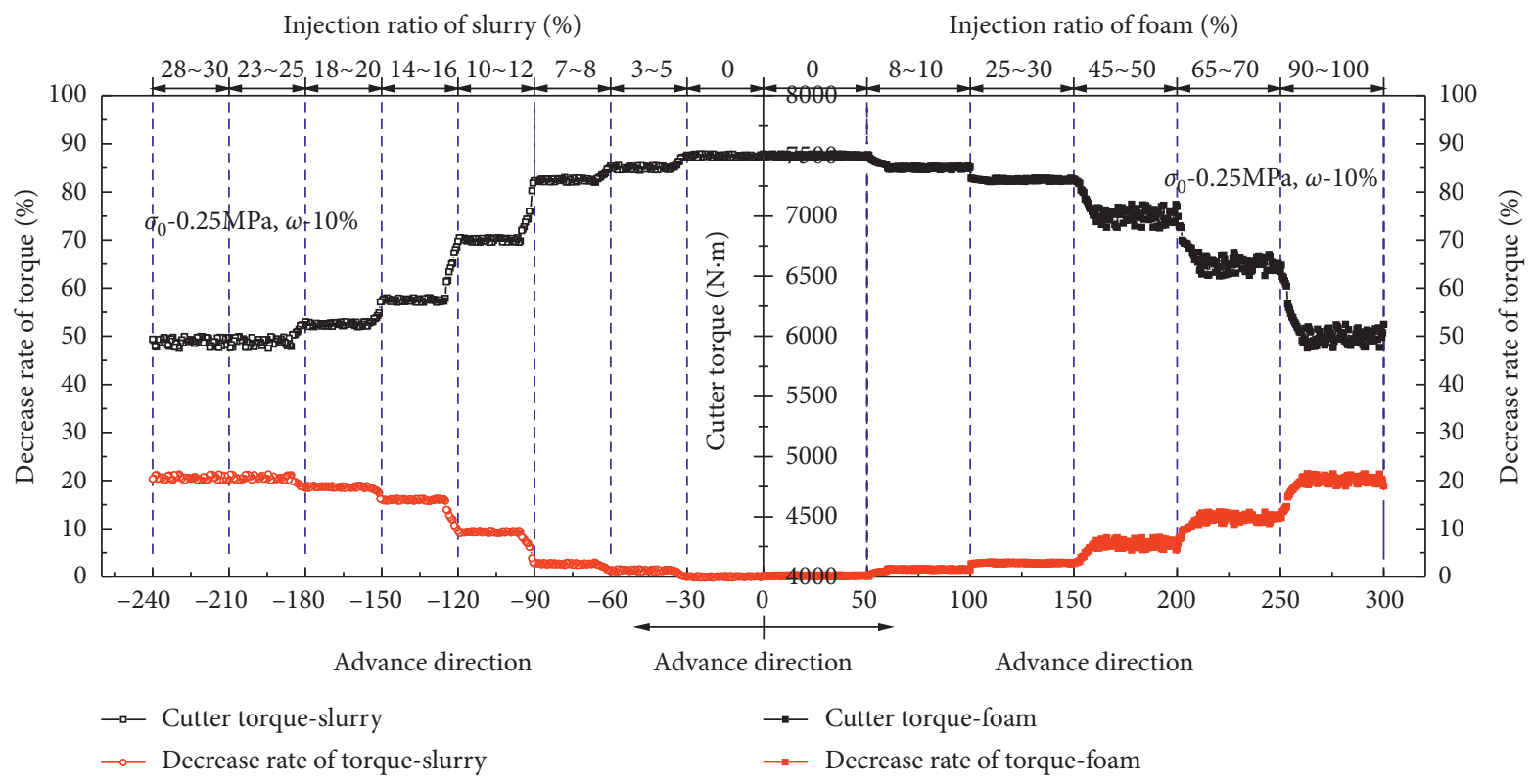

FIgURe 29: Effect of two types of soil conditioners on cutter torque at water content $10 \%$ and soil pressure $0.25 \mathrm{MPa}$.

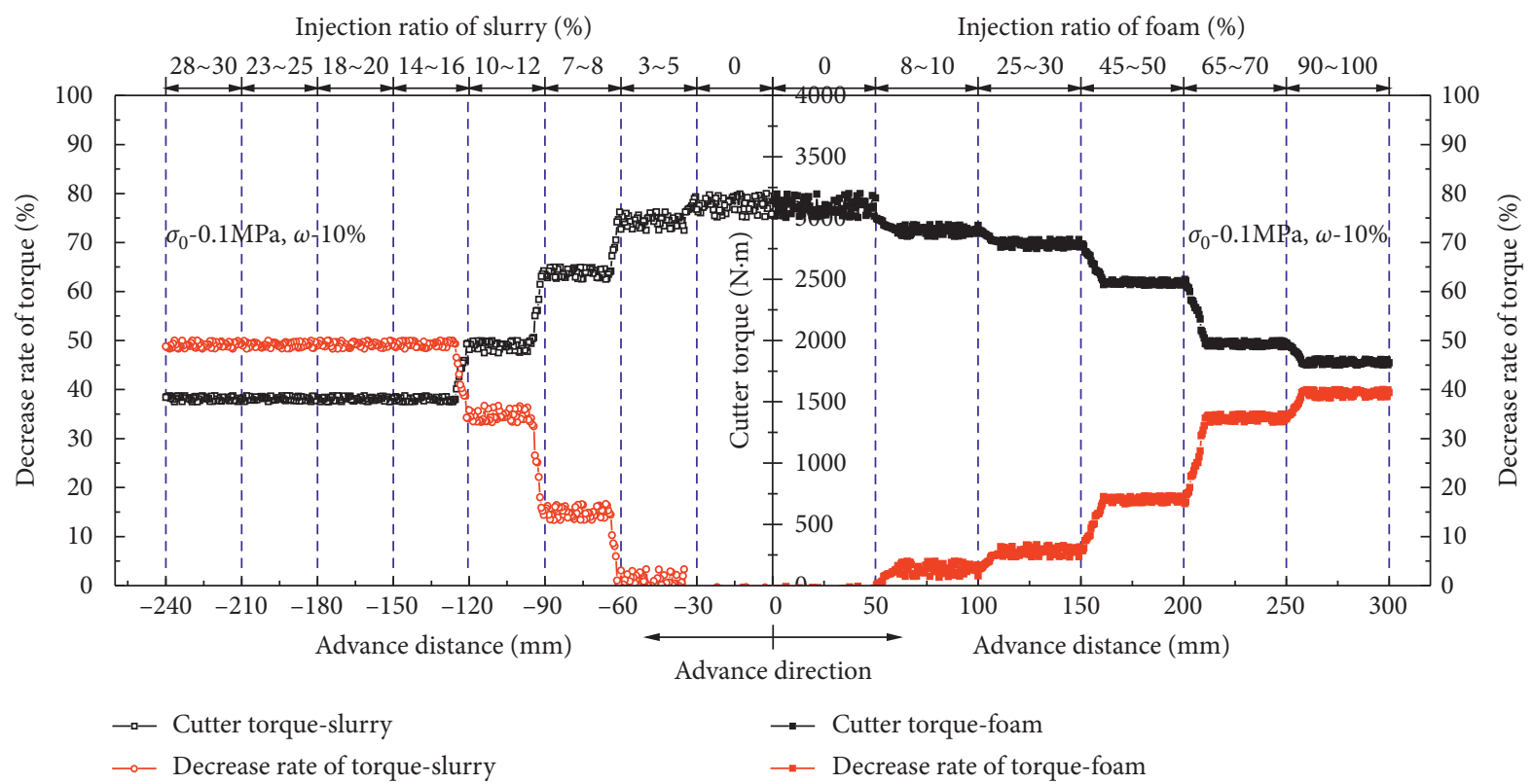

FIgURE 30: Effect of two types of soil conditioners on cutter torque at water content $10 \%$ and soil pressure $0.1 \mathrm{MPa}$.

conducted on a real tunneling project in Wuhan with $\Phi 6.26 \mathrm{~m}$ EPB shield (shown in Figure 31). The tunneling parameters of the cutter head are listed in Table 9. There were totally 60 rings taken for the field experiment, in which the 1st to 30th rings were driven without soil conditioning while the 31st to 60th rings with foam conditioning at different injection ratios, as shown in Figure 8. The foaming parameters adopted in the field test were the same as the laboratory test.

As shown in Figure 32, soil conditioning had an evident effect on shield cutting. During tunneling in the first 30 rings, the cutter torque fluctuated over a wide range from 


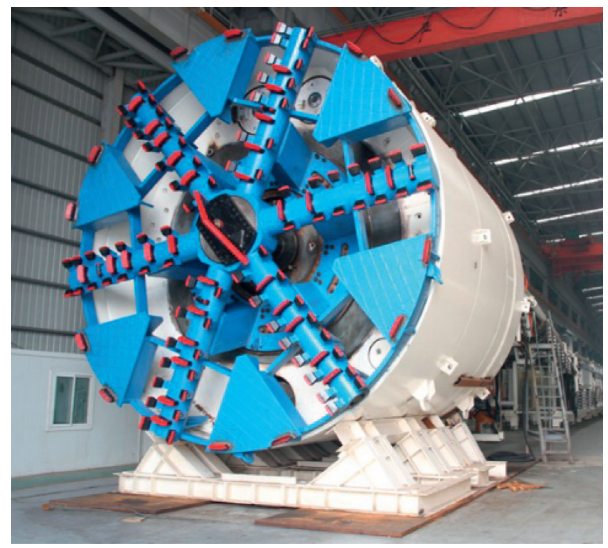

Figure 31: Picture of EPB shield.

TABLE 9: Tunneling parameters of cutter head.

\begin{tabular}{lc}
\hline Mode & EPB \\
\hline Diameter & $6260 \mathrm{~mm}$ \\
Open ratio & $50 \%$ \\
Rated torque & $7206 \mathrm{kN} \mathrm{m}$ \\
Total thrust & $40000 \mathrm{kN}$ \\
Soil pressure & $0.16-0.22 \mathrm{MPa}$ \\
Advance speed & $30 \mathrm{~mm} / \mathrm{min}$ \\
Rotating speed & $1 \mathrm{r} / \mathrm{min}$ \\
\hline
\end{tabular}

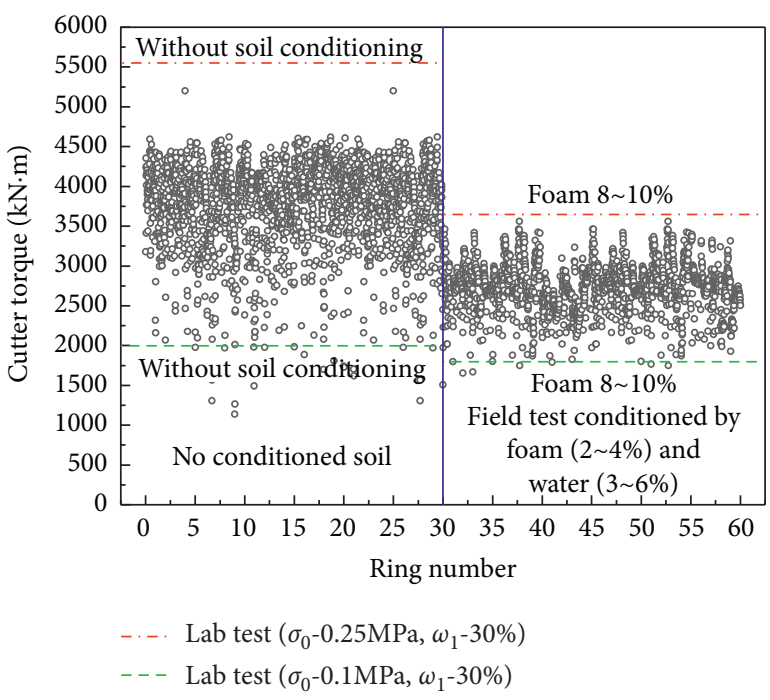

Figure 32: Comparison of laboratory test with field test result.

$3000 \mathrm{kN} \cdot \mathrm{m}$ to $4500 \mathrm{kN} \mathrm{m}$. When the soil was conditioned with foam and water from the 31 th ring onward, the torque sharply decreased to $2200-3200 \mathrm{kN} \mathrm{m}$, about $25 \%-50 \%$ drop.

The predictions of the shield cutter torque based on the laboratory test results were compared with those from the field test in Figure 32, which shows they were in good agreement and most of the measured values were within the range of predicted values.

\section{Conclusion}

In order to realize the effect of soil conditioning on the shield cutting performance and to optimize the conditioning materials, a series of laboratory tests were conducted using a self-developed ground suitability test system. The effect of four key factors was comprehensively investigated on the shield cutting performance and verified by field experiment of a real tunnel project. The major findings were obtained as follows:

(1) The ground suitability test system performed well, and the prediction of the cutter torque based on the test agreed well with the field test. It can prospectively be served as an onsite real time testing equipment for shield tunneling.

(2) The optimal foam parameters are suggested for shield tunneling in silty sand as $3.0 \%$ foam solution concentration, $3.0 \mathrm{~L} / \mathrm{min}$ air flow, $150 \mathrm{~mL} / \mathrm{min}$ liquid flow, $0.3 \mathrm{MPa}$ air pressure, and $0.4 \mathrm{MPa}$ liquid pressure with half-dissipation time and expansion ratio as $1217 \mathrm{~s}$ and 39.81, respectively. The optimal slurry is recommended as $8 \%$ bentonite and $0.5 \%$ CMC with resulted density and funnel viscosity as $1.054 \mathrm{~g} / \mathrm{cm}^{3}$ and $79.36 \mathrm{~s}$, respectively.

(3) The shield cutter torque is also sensitive to the moisture content and confining pressure of silty sand and the injection ratio of conditioners. The torque at moisture content of $10 \%$ is 5 to 7 times more than that at moisture content of $30 \%$ in case of no soil conditioning. When the foam injection ratio exceeds $30 \%$ or the slurry injection ratio exceeds $5 \%$, the shield cutter torque starts to significantly decrease. The maximum decrease in cutter torque by $40 \%-$ $60 \%$ was achieved by optimized soil conditioning, moisture content, and soil pressure. However, the effect of soil conditioning is limited when the injection ratio reaches a certain value.

(4) In comparison, slurry is better than foam in decreasing the cutter torque in silty sand. To achieve 
the same effect of soil conditioning, the injection ratios of foam and slurry should be $45 \%$ and $10 \%$, respectively, to achieve the maximum decrease in the torque at $60 \%$.

\section{Data Availability}

The data used to support the findings of this study are included within the article.

\section{Conflicts of Interest}

The authors declare that they have no conflicts of interest.

\section{Acknowledgments}

This research was funded by the National Basic Research Program of China (973 Program) (Grant no. 2015CB057806). This financial support is gratefully acknowledged.

\section{References}

[1] Z. Chu, Z. Wu, Q. Liu, and B. Liu, "Analytical solutions for deep-buried lined tunnels considering longitudinal discontinuous excavation in rheological rock mass," Journal of Engineering Mechanics, vol. 146, no. 6, Article ID 4020047, 2020.

[2] F. Song, H. Wang, and M. Jiang, "Analytically-based simplified formulas for circular tunnels with two liners in viscoelastic rock under anisotropic initial stresses," Construction and Building Materials, vol. 175, pp. 746-767, 2018.

[3] K. Wu, Z. Shao, S. Qin, and B. Li, "Determination of deformation mechanism and countermeasures in silty clay tunnel," Journal of Performance of Constructed Facilities, vol. 34, no. 1, Article ID 4019095, 2020.

[4] K. Wu and Z. Shao, "Visco-elastic analysis on the effect of flexible layer on mechanical behavior of tunnels," International Journal of Applied Mechanics, vol. 11, no. 3, p. 1950027, 2019.

[5] S.-M. Liao, J.-H. Liu, R.-L. Wang, and Z.-M. Li, "Shield tunneling and environment protection in Shanghai soft ground," Tunnelling and Underground Space Technology, vol. 24, no. 4, pp. 454-465, 2009.

[6] S.-M. Liao, C.-H. Cheng, and L.-S. Chen, "The planning and construction of a large underpass crossing urban expressway in Shanghai: an exemplary solution to the traffic congestions at dead end roads," Tunnelling and Underground Space Technology, vol. 81, pp. 367-381, 2018.

[7] M.-B. Liu and S.-M. Liao, "A case study on the underground rapid transport system (URTS) for the international airport hubs: planning, application and lessons learnt," Tunnelling and Underground Space Technology, vol. 80, pp. 114-122, 2018.

[8] C. Yang, S.-L. Shen, D.-W. Hou, S.-M. Liao, and D.-J. Yuan, "Material properties of the seal gasket for shield tunnels: a review," Construction and Building Materials, vol. 191, pp. 877-890, 2018.

[9] Z. Chu, Z. Wu, B. Liu, and Q. Liu, "Coupled analytical solutions for deep-buried circular lined tunnels considering tunnel face advancement and soft rock rheology effects," Tunnelling and Underground Space Technology, vol. 94, p. 103111, 2019.
[10] C. H. Cheng, S. M. Liao, S. J. Peng, J. W. Zhu, and Y. Liu, "Study on ground suitability of slurry shield in water-rich sandy cobble ground in Shenyang," Chinese Journal of Underground Space and Engineering, vol. 13, pp. 190-196, 2017, in Chinese.

[11] D.-J. Ren, S.-L. Shen, A. Arulrajah, and W.-C. Cheng, "Prediction model of TBM disc cutter wear during tunnelling in heterogeneous ground," Rock Mechanics and Rock Engineering, vol. 51, no. 11, pp. 3599-3611, 2018.

[12] H. T. Jiang, Q. M. Gong, and X. L. Du, "Experimental study on soil conditioning in cobble layer by use of earth pressure balanced machine," Chinese Journal of Geotechnical Engineering, vol. 35, pp. 284-292, 2013, in Chinese.

[13] D. Peila, "Soil conditioning for EPB shield tunnelling," KSCE Journal of Civil Engineering, vol. 18, no. 3, pp. 831-836, 2014.

[14] R. Vinai, C. Oggeri, and D. Peila, "Soil conditioning of sand for EPB applications: a laboratory research," Tunnelling and Underground Space Technology, vol. 23, no. 3, pp. 308-317, 2008.

[15] L. Mori, E. Alavi, and M. Mooney, “Apparent density evaluation methods to assess the effectiveness of soil conditioning," Tunnelling and Underground Space Technology, vol. 67, pp. 175-186, 2017.

[16] D. Peila, A. Picchio, D. Martinelli, and E. D. Negro, "Laboratory tests on soil conditioning of clayey soil," Acta Geotechnica, vol. 11, no. 5, pp. 1061-1074, 2015.

[17] R. Zumsteg and L. Langmaack, "Mechanized tunneling in soft soils: choice of excavation mode and application of soilconditioning additives in glacial Deposits," Engineering, vol. 3, no. 6, pp. 863-870, 2017.

[18] K. Chaidachatorn, J. Suebsuk, S. Horpibulsuk, and A. Arulrajah, "Extended water/cement ratio law for cement mortar containing recycled asphalt pavement," Construction and Building Materials, vol. 196, pp. 457-467, 2019.

[19] C. H. Cheng, G. Q. Zhao, S. M. Liao, and X. B. Huo, "Adaptability study of EPB shield machine in hard clay in Wuhan," Construction Technology, vol. 45, pp. 105-109, 2016, in Chinese.

[20] O. D. G. G. De, M. Thewes, M. S. Diederichs, and L. Lars, "EPB tunnelling through clay-sand mixed soils: proposed methodology for clogging evaluation," Geomechanics and Tunnelling, vol. 11, pp. 375-387, 2018.

[21] Q. Gong, L. Yin, H. Ma, and J. Zhao, “TBM tunnelling under adverse geological conditions: an overview," Tunnelling and Underground Space Technology, vol. 57, pp. 4-17, 2016.

[22] E. A. Zhao, J. Rostami, and K. Talebi, "Experimental study of the effect of conditioning on abrasive wear and torque requirement of full face tunneling machines," Tunnelling and Underground Space Technology, vol. 41, pp. 127-136, 2014.

[23] P. Li, D. Huang, J. Huang, and W. Ding, "Experimental study on soil conditioning of shield construction in hardplastic high-viscosity layer," Journal of Tongji University (Natural Science), vol. 44, pp. 59-66, 2016.

[24] F. Liu, S.-L. Shen, D.-W. Hou, A. Arulrajah, and S. Horpibulsuk, "Enhancing behavior of large volume underground concrete structure using expansive agents," Construction and Building Materials, vol. 114, pp. 49-55, 2016.

[25] L. Mori, M. Mooney, and M. Cha, "Characterizing the influence of stress on foam conditioned sand for EPB tunneling," Tunnelling and Underground Space Technology, vol. 71, pp. 454-465, 2018.

[26] S. Pourmand, H. Chakeri, M. Sharghi, and Y. Ozcelik, "Investigation of soil conditioning tests with three-dimensional 
numerical modeling," Geotechnical and Geological Engineering, vol. 36, no. 5, pp. 2869-2879, 2018.

[27] C. G. O. Salazar, C. Todaro, F. Bosio, E. Bassini, D. Ugues, and D. Peila, "A new test device for the study of metal wear in conditioned granular soil used in EPB shield tunneling," Tunnelling and Underground Space Technology, vol. 73, pp. 212-221, 2018.

[28] S.-L. Shen, D.-W. Hou, J.-L. Zhao, S. Horpibulsuk, and Z.-Y. Yin, "Assessment of internal forces for intermediate anchorage zone of post-tensioned concrete structure," Construction and Building Materials, vol. 64, pp. 370-378, 2014.

[29] P. Sukmak, S. Horpibulsuk, S.-L. Shen, P. Chindaprasirt, and C. Suksiripattanapong, "Factors influencing strength development in clay-fly ash geopolymer," Construction and Building Materials, vol. 47, pp. 1125-1136, 2013.

[30] K. L. Wei, "On the "ideal soil" in the earth pressure balanced shield tunneling," Urban Mass Transit, vol. 10, pp. 67-70, 2007, in Chinese.

[31] K. Elbaz, S.-L. Shen, W.-C. Cheng, A. Arulrajah, and J. N. Shirlaw, "Discussion: cutter-disc consumption during earth pressure balance tunnelling in mixed strata," Proceedings of the Institution of Civil Engineers-Geotechnical Engineering, vol. 171, no. 6, pp. 559-561, 2018.

[32] J. Li, "Key technologies and applications of the design and manufacturing of non-circular TBMs," Engineering, vol. 3, no. 6, pp. 905-914, 2017.

[33] Z. H. Tang, Q. W. Xu, X. A. Yang, Y. Qiu, Z. Y. Gong, and S. Zhang, "Soil conditioning technology for shield tunnelling in a water-rich sandy stratum," Modern Tunnelling Technology, vol. 53, pp. 153-158, 2016.

[34] X. Ye, S. Wang, J. Yang, D. Sheng, and C. Xiao, "Soil conditioning for EPB shield tunneling in argillaceous siltstone with high content of clay minerals: case study," International Journal of Geomechanics, vol. 17, Article ID 5016002, 2016.

[35] S. C. Zhang, S. H. He, Z. P. Zhu, and C. H. Li, "Research on soil conditioning for earth pressure balance shield tunneling in Lanzhou sandy pebble strata with rich water," Rock and Soil Mechanics, vol. 38, pp. 279-286, 2017.

[36] D. Peila, C. Oggeri, and L. Borio, "Using the slump test to assess the behavior of conditioned soil for EPB tunneling," Environmental and Engineering Geoscience, vol. 15, no. 3, pp. 167-174, 2009.

[37] T. Liu, L. S. Chen, and Q. Yao, "Experimental Study of ground conditioning of Earth Pressure Balance (EPB) shield in sandy strata," Tunnel Construction, vol. 37, pp. 1018-1025, 2017, in Chinese.

[38] D. Martinelli, D. Peila, and E. Campa, "Feasibility study of tar sands conditioning for earth pressure balance tunnelling," Journal of Rock Mechanics and Geotechnical Engineering, vol. 7, no. 6, pp. 684-690, 2015.

[39] D. Peila, C. Oggeri, and R. Vinai, "Screw conveyor device for laboratory tests on conditioned soil for EPB tunneling operations," Journal of Geotechnical and Geoenvironmental Engineering, vol. 133, no. 12, pp. 1622-1625, 2007.

[40] D. Peila, A. Picchio, and A. Chieregato, "Earth pressure balance tunnelling in rock masses: laboratory feasibility study of the conditioning process," Tunnelling and Underground Space Technology, vol. 35, pp. 55-66, 2013.

[41] A. Bezuijen and P. E. L. Schaminee, "Tunnelling. a decade of progress. geodelft 1995-2005, in Simulation of the EPB-Shield TBM in Model Tests with Foam as Additive," in Informa UK Limited, pp. 157-163, London, UK, 2006.
[42] T. Merrit, Conditioning for Clay Soils for Tunnelling Machine Screw Conveyors, University of Cambridge, Cambridge, England, 2004.

[43] A. S. Merritt and R. J. Mair, "Mechanics of tunnelling machine screw conveyors: model tests," Géotechnique, vol. 56, no. 9, pp. 605-615, 2006.

[44] T. Nomoto, S. Imamura, T. Hagiwara, O. Kusakabe, and N. Fujii, "Shield tunnel construction in centrifuge," Journal of Geotechnical and Geoenvironmental Engineering, vol. 125, no. 4, pp. 289-300, 1999.

[45] J. Rivas, A. Jiménez, O. Videra, P. Gégout, F. Vallon, and J. Pegon, Reducing the environmental impact of tunnel boring (OSCAR). in Technology Innovation in Underground Construction, G. Beer, Ed., pp. 239-259, CRC Press, Rotterdam, Netherlands, 2009.

[46] P. Sotiris, Properties of Foam/sand Mixtures for Tunnelling Applications, University of Oxford, Oxford, England, 2001.

[47] M. Thewes and C. Budach, "Soil conditioning with foam during EPB tunnelling/. Konditionierung von Lockergesteinen bei Erddruckschilden," Geomechanics and Tunnelling, vol. 3, no. 3, pp. 256-267, 2010.

[48] Q. W. Xu, H. H. Zhu, S. M. Liao, Q. Z. Zheng, and K. Zhou, "Experimental study on EPB shield tunnel construction in soft ground," Chinese Journal of Geotechnical Engineering, vol. 29, pp. 1849-1857, 2007, in Chinese.

[49] C. Budach and M. Thewes, "Application ranges of EPB shields in coarse ground based on laboratory research," Tunnelling and Underground Space Technology, vol. 50, pp. 296-304, 2015.

[50] H. Jiang, Feasibility Study on EPB TBM Applied in Typical Gravel Strata in Beijing Metro, China University of Mining and Technology, Beijing, China, 2012, in Chinese.

[51] Y.-L. Wu, M. Mooney, and M.-S. Cha, "An experimental examination of foam stability under pressure for EPB TBM tunneling," Tunnelling and Underground Space Technology, vol. 77, pp. 80-93, 2018. 